\title{
Tyrosinase-loaded Multicompartment Microreactor toward Melanoma Depletion
}

\author{
Gallardo, Maria Godoy; Labay, Cédric Pierre; Hosta-Rigau, Leticia
}

Published in:

ACS Applied Materials and Interfaces

Link to article, DOI:

10.1021/acsami.8b20275

Publication date:

2019

Document Version

Peer reviewed version

Link back to DTU Orbit

Citation (APA):

Gallardo, M. G., Labay, C. P., \& Hosta-Rigau, L. (2019). Tyrosinase-loaded Multicompartment Microreactor toward Melanoma Depletion. ACS Applied Materials and Interfaces, 11(6), 5862-5876.

https://doi.org/10.1021/acsami.8b20275

\section{General rights}

Copyright and moral rights for the publications made accessible in the public portal are retained by the authors and/or other copyright owners and it is a condition of accessing publications that users recognise and abide by the legal requirements associated with these rights.

- Users may download and print one copy of any publication from the public portal for the purpose of private study or research.

- You may not further distribute the material or use it for any profit-making activity or commercial gain

- You may freely distribute the URL identifying the publication in the public portal

If you believe that this document breaches copyright please contact us providing details, and we will remove access to the work immediately and investigate your claim. 


\title{
Biological and Medical Applications of Materials and Interfaces
}

\author{
Tyrosinase-loaded Multicompartment \\ Microreactor toward Melanoma Depletion \\ Maria Godoy-Gallardo, Cedric Labay, and Leticia Hosta-Rigau
}

ACS Appl. Mater. Interfaces, Just Accepted Manuscript • DOI: 10.1021/acsami.8b20275 • Publication Date (Web): 03 Jan 2019

Downloaded from http://pubs.acs.org on January 7, 2019

\section{Just Accepted}

"Just Accepted" manuscripts have been peer-reviewed and accepted for publication. They are posted online prior to technical editing, formatting for publication and author proofing. The American Chemical Society provides "Just Accepted" as a service to the research community to expedite the dissemination of scientific material as soon as possible after acceptance. "Just Accepted" manuscripts appear in full in PDF format accompanied by an HTML abstract. "Just Accepted" manuscripts have been fully peer reviewed, but should not be considered the official version of record. They are citable by the Digital Object Identifier (DOI®). "Just Accepted" is an optional service offered to authors. Therefore, the "Just Accepted" Web site may not include all articles that will be published in the journal. After a manuscript is technically edited and formatted, it will be removed from the "Just Accepted" Web site and published as an ASAP article. Note that technical editing may introduce minor changes to the manuscript text and/or graphics which could affect content, and all legal disclaimers and ethical guidelines that apply to the journal pertain. ACS cannot be held responsible for errors or consequences arising from the use of information contained in these "Just Accepted" manuscripts. 


\title{
Tyrosinase-loaded Multicompartment Microreactor
}

\section{toward Melanoma Depletion}

\author{
Maria Godoy-Gallardo, Cédric Labay and Leticia Hosta-Rigau*
}

Department of Micro- and Nanotechnology, Center for Nanomedicine and Theranostics, DTU Nanotech, Technical University of Denmark, Building 423, 2800 Lyngby, Denmark

KEYWORDS. Enzymes, liposomes, macromolecular drug delivery, melanoma, microreactors, shear stress

\begin{abstract}
Melanoma is a malignant skin cancer occurring with increasing prevalence with no effective treatment. A unique feature of melanoma cells is that they require higher concentrations of L-tyrosine (L-tyr) for expansion than normal cells. As such, it has been demonstrated that dietary L-tyr restriction lowers systemic L-tyr and suppresses melanoma advancement in mice. Unfortunately, this diet is not well tolerated by humans. An alternative approach to impede melanoma progression will be to administer the enzyme tyrosinase (TYR) which converts L-tyr into melanin. Herein, a multicompartment carrier consisting of a polymer shell entrapping thousands of liposomes is employed to act as a microreactor depleting L-tyr in the presence of melanoma cells. It is shown that the TYR enzyme can be incorporated within the liposomal subunits with preserved catalytic activity. Aiming to mimic the dynamic environment at the tumor site, L-tyr conversion is conducted by co-culturing melanoma cells and microreactors in a
\end{abstract}


microfluidic set-up with applied intra-tumor shear stress. It is demonstrated that the microreactors are concurrently depleting L-tyr, which translates into inhibited melanoma cell growth. Thus, the first microreactor where the depletion of a substrate translates into anti-tumor properties in vitro is reported.

\section{INTRODUCTION}

Melanoma is currently the fifth most frequent type of cancer and the most threatening form of skin cancer. ${ }^{1}$ The incidence rate of melanoma has increased badly in the last century, ${ }^{2}$ and it is the cause of the largest part of skin cancer-related deaths. ${ }^{3}$ Despite extensive research, especially towards the development of targeted therapies and immunotherapies, ${ }^{4}$ current strategies have only demonstrated noticeable efficacy in some patients and their effect in the long-term survival is still variable. ${ }^{5}$ As such, newer therapeutic approaches are required for what is arguably the most difficult cancer to treat. ${ }^{5}$

A unique characteristic of melanoma cells is that the amino acid (AA) L-tyrosine (L-tyr) is crucial for their metabolic cycle and malignant melanomas require higher amounts of L-tyr to advance as compared to normal cells. ${ }^{6,7}$ L-tyr is an AA present in the body from protein metabolism, consumption of nutrients and phenylalanine hydroxylation. ${ }^{8}$ Research studies have demonstrated that lowering systemic levels of L-tyr using an L-tyr- and L-phenylalanine-restricted dietary intake can prevent the advancement of melanoma both in vitro and in vivo. ${ }^{9-11}$ Unfortunately, low L-tyr diets have several drawbacks which include: a limited effect in lowering systemic L-tyr levels (to only $\sim 67 \%$ of the normal levels); $;{ }^{12}$ the extended treatment duration required for efficacy; ${ }^{8}$ and, what is worse, the fact that low L-tyr diets are not well tolerated by melanoma patients causing them severe adverse effects. ${ }^{13}$ Due to the associated detrimental effects, it has not been possible to conduct proper clinical trials by making use of restricted L-tyr diets. An alternative option to lower 
the amount of L-tyr needed for melanoma progression would be the use of the enzyme tyrosinase (TYR). TYR depletes the AA L-tyr by a series of reactions and intermediate products that result in the formation of melanin (Scheme 1 and Figure S1, Supporting Information). ${ }^{14}$ However, the administration of enzymes has some limitations and risks related to their bioavailability, toxicity, immune response and fast degradation upon administration. ${ }^{15}$ In particular, TYR has an exceptional short half-life of only about several minutes following intravenous administration. ${ }^{8}$ This fact will involve repeated injections resulting in immunological problems and very poor patients compliance. Due to those challenges, the concept of treating melanoma with TYR has been around for some years with quite limited success. ${ }^{8,16,17}$ Research efforts towards the delivery of TYR for melanoma treatment include: to chemically crosslink TYR to hemoglobin $(\mathrm{Hb})$ to form a polyHb-TYR complex ${ }^{16}$ or TYR encapsulation within polymeric capsules for oral administration. ${ }^{18}$ While the first approach could lower the systemic L-tyr levels to $\sim 13 \%$ in mice, which translated into delayed melanoma growth, ${ }^{16}$ this procedure had several drawbacks. The required chemical modification of TYR to create the polyHb-TYR complex altered its catalytic properties. Additionally, what is worse, recent years have revealed polyHb to have important toxic effects due to its nitric oxide scavenging properties that result in the associated cardiovascular problems and higher mortality rates. ${ }^{19,20}$ In contrast, the second approach results in a more appropriate system for the administration of enzymes since, by making use of an encapsulation platform, the TYR enzyme's structure and catalytic activity are preserved. ${ }^{18}$ However, follow up studies towards melanoma progression using this system both in vitro and in vivo still remain to be performed.

Despite the initial encouraging results, it is worth noting that these examples date back from the early 2000s and, thanks to the advances in materials science, recent years have spurred progress in 
a variety of different enzymatic micro/nanoreactors. ${ }^{21-23}$ The creation of encapsulation platforms entrapping enzymes protecting them from the external milieu and, thus, allowing them to conduct their enzymatic activity for a prolonged period of time, is envisioned to surmount the hurdles of enzyme delivery. The most prominent architectures able to operate as enzymatic micro/nanoreactors include liposomes, ${ }^{24}$ polymersomes, ${ }^{25,26}$ polymeric capsules and nanoparticles, ${ }^{27-29}$ and silica-based systems. ${ }^{30,31}$ Although the aforementioned structures can increase the applicability of enzymes by affording protection towards proteases, minimizing enzyme clearance while reducing their immunogenicity; it should be noted that they are all made of a single constituent material (i.e., lipids, polymers or silica). The exception are hybrid systems composed of thousands of liposomes entrapped within a polymeric carrier capsule. ${ }^{32,33} \mathrm{By}$ combining these two inherently different building blocks, this multicompartment carrier exploits the advantages of both systems while diminishing some of their defficiencies. ${ }^{34-36}$ Liposomes are well suited to encapsulate fragile biomolecules such as enzymes due to their similarity to biological cell membranes. However, they have also some important shortcomings such as in vivo structural instability and scarce control over degradation. ${ }^{37,38}$ On the other hand, the polymer capsule overcomes the liposomes limitations by providing structural integrity and preventing liposomes rapid degradation. ${ }^{34}$ Importantly, the polymeric carrier shell is semi-permeable allowing the substrates and products to permeate in and out of the carrier, a crucial feature to perform as (enzymatic) microreactors in a continuous manner.

Herein we employ this multicompartment platform to encapsulate TYR and inhibit melanoma cell growth in vitro (Scheme 1). By using such a hybrid carrier, TYR will be entrapped within biomimetic liposomes avoiding misfolding or denaturation while, thanks to the polymer carrier shell, the liposomes will be stopped from interacting with the degrading proteases of the intra- 
tumor environment. ${ }^{39}$ It is important to note that, in contrast to previous approaches which aimed to administer TYR to deplete L-tyr systemically, our multicompartment platform is envisioned to act as an enzyme microreactor in the tumor site following up intra-tumor administration (e.g., as an injectable implant). By diminishing the amount of L-tyr substrate locally, we anticipate an enhanced anti-tumor effect towards melanoma progression.

Herein, we report a new class of TYR-loaded microreactors (Scheme 1) and demonstrate their ability to deplete L-tyr followed by the inhibition of melanoma cells growth. In particular, we (i) optimize the assembly of microreactors containing different amounts of TYR-loaded liposomes, (ii) demonstrate that the encapsulated TYR preserves its catalytic activity by depleting L-tyr in a test tube, (iii) show the absence of intrinsic toxicity for the empty microreactors as well as their integration within melanoma cells, (iv) evaluate the potential of the as-prepared microreactors to inhibit melanoma cells growth in vitro both in static and in intra-tumor mimicking dynamic conditions.

\section{EXPERIMENTAL SECTION}

2.1. Materials. Triton $\mathrm{X}-100$, sodium hydroxide $(\mathrm{NaOH})$, hydrochloric acid, chloroform, 4-(2hydroxyethyl)piperazine-1-ethanesulfonic acid (HEPES), dimethylchloride, bovine serum albumin (BSA), paraformaldehyde (PFA), $\operatorname{Resomer~}^{\circledR}$ RG 502 H poly(D,L-lactic-co-glycolic acid) (PLGA, $\mathrm{M}_{\mathrm{w}} \sim 12-13 \mathrm{kDa}$ ), poly(vinyl alcohol) (PVA, $\mathrm{M}_{\mathrm{w}} \sim 13-23 \mathrm{kDa}$ ), poly(allylamine hydrochloride) (PAH, $\mathrm{M}_{\mathrm{w}} \sim 17.5 \mathrm{kDa}$ ), poly(styrenesulfonic acid sodium salt) $\left(\mathrm{PSS}, \mathrm{M}_{\mathrm{w}} \sim 77 \mathrm{kDa}\right.$ ), tyrosinase from mushroom (TYR), L-tyrosine (L-tyr), trypsin from bovine pancreas, dimethyl sulfoxide (DMSO), sodium bicarbonate $\left(\mathrm{NaHCO}_{3}\right)$, Phalloidin-Tetramethylrhodamine B isothiocyanate (Phalloidin-TRITC), 3,3'-dioctadecyloxacarbocyanine perchlorate (DiO), penicillin-streptomycin, sodium pyruvate, Dulbecco's phosphate buffered saline (PBS) and 
Dulbecco's Modified Eagle's Medium-high glucose D5796 (DMEM) were purchased from Sigma-Aldrich (Sant Louis, MO, USA). 1,2-dimyristoyl-sn-glycero-3-phosphocholine (DMPC, phase transition temperature $24^{\circ} \mathrm{C}$ ), 1,2-dipalmitoyl-sn-glycero-3-phosphocholine (DPPC, phase transition temperature $\left.41{ }^{\circ} \mathrm{C}\right)$ and 1-palmitoyl-2-\{6-[(7-nitro-2-1,3-benzoxadiazol-4yl)amino]hexanoyl\}-sn-glycero-3-phosphocholine (NBD-PC) were obtained from Avanti Polar Lipids (Alabaster, AL, USA). PrestoBlue ${ }^{\circledR}$ cell viability reagent, fluorescein isothiocyanate (FITC) and Pierce ${ }^{\mathrm{TM}}$ BCA Protein Assay Kit was obtained from Thermo Fisher Scientific (Waltham, MA, USA). Mus musculus skin melanoma B16-F10 (ATCC® CRL-6475 ${ }^{\mathrm{TM}}$ ) were purchased from American Type Culture Collection (ATCC, USA) while RAW 264.7 cell line (ATCC $\AA$ TIB-71 ${ }^{\mathrm{TM}}$ ) were purchased from European Collection of Authenticated-Culture Collections (ECACC, UK).

The different buffers employed were prepared with ultrapure water (Milli-Q gradient A 10 system, resistance $18 \mathrm{MV} \mathrm{cm}$, TOC $<4$ ppb, EMD Millipore, USA). The concentration of HEPES buffer was $10 \mathrm{mM}$ HEPES (pH 7.4).

2.2. Enzymatic Reaction in a Test Tube. To assess the kinetics of the TYR reaction, different amounts of TYR $(0,4,6,12$ and $18 \mathrm{U})$ were dissolved in either PBS or DMEM $(200 \mu \mathrm{L})$ containing L-tyr $(0.66 \mathrm{mM})$ and incubated at $37^{\circ} \mathrm{C}$ for different time intervals. After the required incubation time, the obtained melanin product was quantified by adding $\mathrm{NaOH}(20 \mu \mathrm{L}, 1 \mathrm{M})$ and incubating for $5 \mathrm{~h}$ at $37^{\circ} \mathrm{C}$ under continuous stirring. Next, the absorbance of the dissolved melanin product was monitored at $475 \mathrm{~nm}$ employing a multimode plate reader (Tecan Spark, TECAN, Switzerland).

2.3. Liposomes Assembly. Liposomes were fabricated according to the thin-film hydration method. Briefly, DMPC and DPPC at a weight ratio 7:3 were dissolved in chloroform. Following 
solvent removal applying vacuum over $1 \mathrm{~h}$, the resulting lipid film was hydrated in HEPES buffer ( $1 \mathrm{~mL}$ for $2.5 \mathrm{mg}$ of lipids) at $37^{\circ} \mathrm{C}$ under constant vortexing. Upon dissolution of the lipid film, the resulting dispersion was extruded 11 times at $37^{\circ} \mathrm{C}(100 \mathrm{~nm}$ nucleopore polycarbonate filters (drain disc10 mm PE, Whatman, UK) were employed).

For fluorescently labelled liposomes $\left(\mathrm{L}^{\mathrm{F}}\right) 0.5 \mathrm{wt} \%$ of either NBD-PC (for flow cytometry and optimization of microreactors assembly) or $\mathrm{DiO}$ (to assemble microreactors for assessing their cell integration) was added to the lipids dissolved in chloroform. For liposomes encapsulating the TYR enzyme $\left(L_{T Y R}\right)$, the lipid film was hydrated with the required units of TYR in HEPES buffer (1 $\mathrm{mL}$ ). To dissolve the lipid film alternating vortexing and submersion into a water bath at $42{ }^{\circ} \mathrm{C}$ for 30 min was employed. After extrusion, non-encapsulated TYR was removed by dialysis using a $300 \mathrm{kDa}$ dialysis membrane (Spectrum lab, Netherlands). The as-prepared liposomes were stored at $4^{\circ} \mathrm{C}$.

2.4. Enzyme Encapsulation. To determine the amount of TYR entrapped/associated with liposomes, $\mathrm{L}_{\mathrm{TYR}}\left(200 \mu \mathrm{L}, 2.5 \mathrm{mg} \mathrm{mL}^{-1}\right)$ were disassembled using Triton $\mathrm{X}(1 \%$ Triton $\mathrm{X}-100$ in HEPES buffer). The amount of total enzyme was quantified by means of a bicinchoninic acid (BCA) assay following the commercial protocol. The encapsulation efficiency (EE) was assessed as described in the Supporting Information. To distinguish the amount of TYR encapsulated within or associated with $\mathrm{L}_{\mathrm{TYR}}$ membrane, $\mathrm{L}_{\mathrm{TYR}}\left(11 \mu \mathrm{L}, 2.5 \mathrm{mg} \mathrm{mL}^{-1}\right)$ were incubated in a $\mathrm{L}$-tyr solution $\left(200 \mu \mathrm{L}, 1 \mathrm{M}\right.$ ) at both 4 and $42{ }^{\circ} \mathrm{C}$ under continuous stirring for up to 7 days. At different time intervals, the samples were spun down ( $3 \mathrm{~min}, 8 \mathrm{rpm}$ ) employing a bench top centrifuge (MiniSpin, Eppendorf AG, Germany) and the supernatant removed. PBS $(200 \mu \mathrm{L})$ and $\mathrm{NaOH}(20 \mu \mathrm{L}, 1 \mathrm{M})$ were added to the supernatants and the mixture was incubated for $5 \mathrm{~h}$ at $37^{\circ} \mathrm{C}$ under continuous 
stirring. Finally, the absorbance of the dissolved melanin product was monitored at $475 \mathrm{~nm}$ employing the Tecan Spark multimode plate reader.

2.5. Synthesis of PLGA Microspheres. PLGA microspheres were synthesized following a previously reported water-in-oil-in-water $(\mathrm{w} / \mathrm{o} / \mathrm{w})$ double emulsion procedure with minor modifications ${ }^{40}$ Briefly, PLGA (240 mg) was dissolved in anhydrous dichloromethane $(3 \mathrm{~mL})$ while BSA $(144 \mathrm{mg})$ was dissolved in deionized water $(600 \mu \mathrm{L})$. The mixture was emulsified with an ultrasonic homogenizer (150 VT Ultrasonic Homogenizer, Biologics, Inc., USA) at $50 \mathrm{~W}$ for $10 \mathrm{~s}$ in an ice bath. The resulting emulsion was vortexed for $5 \mathrm{~s}$ and emulsified again for $10 \mathrm{~s}$ at $50 \mathrm{~W}$ with the ultrasonic homogenizer. A PVA solution (4\% PVA in $\mathrm{H}_{2} \mathrm{O}, 15 \mathrm{~mL}$ ) was added to the resultant emulsion (w/o) and emulsified again by means of a homogenizer (Ultra-Turrax ${ }^{\circledR} \mathrm{T} 25$ digital, IKA-Werke GmbH \& CO., Germany) at $6000 \mathrm{rpm}$ for $50 \mathrm{~min}$ at room temperature (RT) to form a double emulsion (w/o/w). For solvent extraction, the double emulsion was added to a PVA solution $\left(0.4 \%\right.$ PVA in $\left.\mathrm{H}_{2} \mathrm{O}, 300 \mathrm{~mL}\right)$ and stirred magnetically at $800 \mathrm{rpm}$ overnight. The obtained microspheres were allowed to precipitate for $4 \mathrm{~h}$ and were washed with deionized water for at least five times.

2.6. Characterization of PLGA Microspheres. Differential interference contrast (DIC) microscopy images of PLGA microspheres were taken employing an Olympus microscope IX83 (Olympus Danmark A/S, Denmark) equipped with a DIC slider and a $63 \times$ oil immersion objective. To assess the size of the microspheres, four independent batches were analyzed and 100 microspheres per batch were measured by making use of the Image $\mathbf{J}$ software.

2.7. Morphological Analysis of PLGA Microspheres. Surface morphology of the PLGA microspheres was analyzed by scanning electron microscopy (SEM) employing a FEI Quanta 200 ESEM FEG (FEI-Company, USA). First, the microspheres were coated with gold $(1.4 \mathrm{~nm}$ 
thickness) using a Q150T ES Turbo-Pumped Sputter (Quorum technologies, UK) and several images were taken at a working distance of $10 \mathrm{~mm}$ and a potential of $5 \mathrm{kV}$.

2.8. Dynamic Light Scattering (DLS) and Zeta (ל)-Potential. The size, polydispersity (PD) and $\zeta$-potential of liposomes and the $\zeta$-potential measurements of the coated PLGA microspheres at different steps of the assembly were assessed by adding $20 \mu \mathrm{L}$ of a suspension of coated microspheres $\left(1 \times 10^{4}\right.$ microspheres $\left.\mu \mathrm{L}^{-1}\right)$ to Milli-Q water $(2 \mathrm{~mL})$. The measurements were carried out in triplicate at $25^{\circ} \mathrm{C}$ in a ZetaPALS $\zeta$-potential analyzer (Brookhaven Instruments Corporation, USA).

2.9. Polymer Labelling. PAH was fluorescently labelled with FITC by adding a solution of FITC (3.7 $\mathrm{mg}$ in $300 \mu \mathrm{L}$ DMSO) to a PAH solution (30 mg in $6 \mathrm{~mL} 0.05 \mathrm{M} \mathrm{NaHCO}_{3} \mathrm{pH} 10$ buffer) in a dropwise manner. Next, the reaction mixture was stirred overnight at RT. Next, the excess of FITC was thoroughly removed by two days dialysis against Milli-Q water followed by freezedrying to obtain $\mathrm{PAH}^{\mathrm{F}}$.

2.10. Microreactors Assembly. A suspension of PLGA microspheres $\left(\sim 1 \times 10^{4}\right.$ particles $\left.\mu \mathrm{L}^{-1}\right)$ was incubated with PAH (40 $\left.\mathrm{mg} \mathrm{mL}^{-1}, 15 \mathrm{~min}\right)$ followed by $3 \times$ washes in HEPES buffer (4000 rpm, 45 s). All centrifugation steps were conducted making use of a benchtop centrifuge (MiniSpin, Eppendorf AG, Germany). Up to three bilayers of alternating liposomes (either $\mathrm{L}^{\mathrm{F}}$, $\mathrm{L}^{\mathrm{F}_{\mathrm{TYR}}}$ or $\left.\mathrm{L}_{\mathrm{TYR}}\right)(3.6 \mathrm{mM}, 50 \mathrm{~min})$ and PAH $\left(8 \mathrm{mg} \mathrm{mL}^{-1}, 10 \mathrm{~min}\right)$ were absorbed onto the PLGA microspheres. Each layer deposition step was followed by $3 \times$ washes in HEPES buffer. Next, the carrier shell was assembled by the deposition of two bilayers of alternating PSS $\left(1 \mathrm{mg} \mathrm{mL}^{-1}, 10\right.$ min) and PAH (8 mg mL $\left.\mathrm{mL}^{-1}, 10 \mathrm{~min}\right)$ and a final layer of PSS (1 $\left.\mathrm{mg} \mathrm{mL}^{-1}, 10 \mathrm{~min}\right)$. Again, each layer deposition step was followed by $3 \times$ HEPES buffer washing steps. 
2.11. Flow Cytometry. The number of microreactors and the fluorescence intensity of the microreactors entrapping $\mathrm{L}^{\mathrm{F}}$ were assessed by flow cytometry. A BD Accuri cytometer instrument (BD Biosciences, Sparks, USA) and an Accuri C6 auto sampler flow cytometer plus software (BD Biosciences, Sparks, USA) were employed. At least two experiments were conducted independently and at least 20000 events were analyzed for each experiment. The fluorescence intensity of the microreactors due to the encapsulated $\mathrm{L}^{\mathrm{F}}$ was measured at an excitation wavelength of $488 \mathrm{~nm}$ and a filter of $533 / 30 \mathrm{~nm}$.

2.12. Confocal Laser Scanning Microscopy (CLSM). Microreactors loaded with $L^{F}$ were imaged with a Leica TCS SP5 CLSM (Leica Microsystems GmbH). The CLSM was equipped with an Ar laser with excitation/emission wavelengths of 476/510-550 nm, respectively and a $63 \times$ water immersion objective.

2.13. DIC Microscopy. An Olympus Inverted IX83 microscope was employed to take DIC images of the microreactors. The microscope was equipped with a $63 \times$ oil immersion objective.

\subsection{Quartz Crystal Microbalance with Dissipation Monitoring (QCM-D). A Q-sense E1} instrument (Biolin Scientific) was employed to monitor the deposition of the different layers on a gold crystal (QSX301, Q-sense Biolin Scientific, Sweden). A $200 \mathrm{~mL} \mathrm{~min}^{-1}$ as flow rate was employed. Prior performing the measurements, the gold sensors were cleaned by exposure to UV/ozone for $10 \mathrm{~min}$ followed by immersion in a solution of Milli-Q: ammonia: hydrogen peroxide $(5: 1: 1 \mathrm{v} / \mathrm{v})$ for $5 \mathrm{~min}$ at $75^{\circ} \mathrm{C}$. Next, the gold sensors were rinsed with Milli-Q, dried with nitrogen and exposed to UV/ozone for $10 \mathrm{~min}$. Next, after the HEPES baseline stabilization, a solution of PAH (40 mg mL-1) was loaded in the chamber reaching surface saturation. The unbound polymer was washed away with buffer. Next, the resulting PAH-coated surface was exposed to $\mathrm{L}_{\mathrm{TYR}}\left(2.5 \mathrm{mg} \mathrm{mL}^{-1}\right)$ for $60 \mathrm{~min}$ until surface saturation was reached. The excess of $\mathrm{L}_{\mathrm{TYR}}$ was 
washed away with HEPES buffer and the surface was again exposed to a PAH solution (8 $\mathrm{mg} \mathrm{mL}^{-}$ $\left.{ }^{1}\right)$. Following surface saturation and rinsing with buffer, the process was repeated until three bilayers of $\mathrm{L}_{\mathrm{TYR}}$-PAH were deposited onto the crystal. Finally, the surface was exposed to a PSS solution $\left(1 \mathrm{mg} \mathrm{mL}^{-1}\right)$ reaching surface saturation followed by washing off the PSS excess with HEPES buffer. The experiments were carried out at $25{ }^{\circ} \mathrm{C}$ and normalized frequency and dissipation values using the third harmonic are reported.

2.15. Enzymatic Kinetics of Microreactors. To study the enzymatic reaction kinetics employing TYR-loaded microreactors, $200 \mu \mathrm{L}$ of DMEM without phenol red containing $1 \times 10^{6}$ microreactors entrapping three $\mathrm{L}_{\mathrm{TYR}}$ layers $\left(\mathrm{MR} 3 \mathrm{~L}_{\mathrm{TYR}}\right)$ were incubated at $37{ }^{\circ} \mathrm{C}$ under continuous stirring. As controls, MR3 $\mathrm{L}_{\mathrm{TYR}}$ at RT, free $\mathrm{TYR}$ at both $37{ }^{\circ} \mathrm{C}$ and $\mathrm{RT}$, empty microreactors (MR3L) at $37{ }^{\circ} \mathrm{C}$ and DMEM only at $37^{\circ} \mathrm{C}$ were employed. At different time points, the melanin precipitate of the different samples was dissolved by adjusting the $\mathrm{pH}$ to 11 (adding $20 \mu \mathrm{L} \mathrm{NaOH} 1 \mathrm{M}$ ) followed by overnight incubation at $37^{\circ} \mathrm{C}$. The dissolved melanin product was quantified by monitoring the absorbance at $475 \mathrm{~nm}$ employing the multimode plate reader. ${ }^{41}$

For the repeated enzymatic conversion, $1 \times 10^{6} \mathrm{MR} \mathrm{L}_{\mathrm{TYR}}$ were incubated in DMEM without phenol red $(200 \mu \mathrm{L})$ at $37^{\circ} \mathrm{C}$ under continuous stirring for up to 5 days. At different time intervals, the samples were spun down (45 s, $4000 \mathrm{rpm})$ employing the bench top centrifuge and the supernatant was replaced by fresh DMEM without phenol red $(200 \mu \mathrm{L})$. The melanin precipitate of the supernatants was dissolved by adjusting the $\mathrm{pH}$ to 11 (adding $20 \mu \mathrm{L} \mathrm{NaOH} 1 \mathrm{M}$ ) followed by incubation at $37{ }^{\circ} \mathrm{C}$ overnight. Next, the absorbance of the dissolved melanin product was monitored at $475 \mathrm{~nm}$ using the multimode plate reader.

2.16. Cell Experiments. Mus musculus B16-F10 melanoma cells and the macrophage RAW 264.7 cell line were cultured in cell media consisting of DMEM supplemented with $10 \%(\mathrm{v} / \mathrm{v})$ fetal 
bovine serum (FBS), 1\% (v/v) sodium pyruvate, $1 \%(\mathrm{v} / \mathrm{v})$ penicillin/streptomycin $\left(10000 \mathrm{U} \mathrm{mL}^{-}\right.$ ${ }^{1}$ and $\left.10 \mu \mathrm{g} \mathrm{mL}^{-1}\right)$ and $2 \%(\mathrm{v} / \mathrm{v}) \mathrm{HEPES}$ at $37{ }^{\circ} \mathrm{C}$ and $5 \%(\mathrm{v} / \mathrm{v}) \mathrm{CO}_{2}$. For cell culture, the medium was exchanged every two days and cells between passages three and seven (for B46-F10) and between passages four and six (for RAW 264.7) were used in all experiments. A cell scraper was employed to detach sub-confluent RAW 264.7 cells from the culture flask. For B16-F10 cells, subconfluent cells were detached from the culture flask by adding $3 \mathrm{~mL}$ trypsin. Both RAW 264.7 and B16-F10 cells were aspirated and re-suspended in cell media. Appropriate aliquots of the asprepared cell suspension were added into new culture flasks. All cell experiments in the manuscript were conducted in triplicate. At least three independent experiments were carried out. For static conditions, for B16-F10, the cells were seeded at a density of $10000,6000,4000,3000$ and 2000 cells per well for studies of 1,2, 3, 4 and 5 days, respectively, in $300 \mu \mathrm{L}$ of full cell media (for experiments performed in 96-well plates). For experiments conducted in 48-well plates, the cells were seeded at a density of $20000,12000,6000,5000$ and 4000 cells per well for studies of 1,2, 3, 4 and 5 days, respectively, in $500 \mu \mathrm{L}$ of full cell media. For RAW 264.7, the cells were seeded at a density of 30000,15000 and 8000 cells per well for studies of 1,2 and 3 days, respectively, in $300 \mu \mathrm{L}$ of full cell media (the experiments were conducted in 96-well plates). For dynamic conditions, B16-F10 melanoma cells were seeded at a density of 18000,11000 and 8000 cells in a closed perfusion channel ( $\mu$-slide $\mathrm{VI}^{0.4}$ six-well, ibiTreat channels, Ibidi $\mathrm{GmbH}$, Munich, Germany) for studies of 1, 2 and 3 days, respectively, in $150 \mu \mathrm{L}$ of full cell media. Prior adding the samples, the cells were allowed to attach for approximately $24 \mathrm{~h}$ at $37^{\circ} \mathrm{C}$ and $5 \% \mathrm{CO}_{2}$.

2.17. Microreactors Biocompatibility. Empty microreactors (MR3L) at different microreactorsto-cell ratios (100:1 and 50:1) were added to the cells following incubation for different time intervals (up to 5 days) at $37{ }^{\circ} \mathrm{C}$ and $5 \% \mathrm{CO}_{2}$. As controls, cells without microreactors exposure 
(high control) and cell medium only (low control) were considered. After the different incubation times, the cells were washed $2 \times$ in PBS $(200 \mu \mathrm{L})$ and $1 \times$ in a mixture of DMEM and PrestoBlue ${ }^{\circledR}$ cell viability reagent $\left(90 \mu \mathrm{L}\right.$ DMEM $+10 \mu \mathrm{L}$ PrestoBlue $\left.{ }^{\circledR}\right)$. Next, the mixture of DMEM and PrestoBlue ${ }^{\circledR}$ cell viability reagent was added to the different wells and incubated for $1 \mathrm{~h}$ at $37{ }^{\circ} \mathrm{C}$ in the dark. Finally, the fluorescence intensity of the reduced resazurin product was assessed at excitation/emission wavelength of 535/615 nm using the multimodal plate reader. The normalized cell viability was calculated as follows: normalized cell viability $(\%)=($ experimental value - low control value) $/($ high control value - low control value $) \times 100$.

2.18. Microreactors Integration within B16-F10 Melanoma Cells. Sterile cover glasses were placed in the different wells of 48-well plates. Next, the B16-F10 cells were seeded either in the 48-well plates (static conditions) or in the channels of the microfluidic set up (dynamic conditions). Following $24 \mathrm{~h}$ of cell attachment, TYR-loaded microreactors either assembled employing $\mathrm{PAH}^{\mathrm{F}}$ $\left(\mathrm{MR} 3 \mathrm{~L}_{\mathrm{TYR}}-\mathrm{PAH}^{\mathrm{F}}\right)$ or $\mathrm{L}^{\mathrm{F}}{ }_{\mathrm{TYR}}\left(\mathrm{MR} 3 \mathrm{~L}^{\mathrm{F}}{ }_{\mathrm{TYR}}\right)$ were added at a microreactors-to-cell ratio 50:1 were added to the wells (static conditions) or to the channels (dynamic conditions). For dynamic conditions, the syringes of the pump system (loaded with $7.5 \mathrm{~mL}$ of complete cell media) were connected to the channels. The Ibidi Pump System (Ibidi GmbH, Germany) was used to apply two different controlled shear stresses $\left(\tau=0.5 \mathrm{dyn} \mathrm{cm}^{-2}(\tau 0.5)\right.$ and $\left.\tau=20 \mathrm{dyn} \mathrm{cm}^{-2}(\tau 20)\right)$ for different time intervals. The cells were then incubated at different time-points at $37{ }^{\circ} \mathrm{C}$ and $5 \% \mathrm{CO}_{2}$. As controls, cells without microreactors exposure at both $\tau 0.5$ and $\tau 20$ for dynamic conditions and at $\tau 0$ for static conditions, were considered. After the different incubation times, the cells from either the wells or the channels were washed in PBS $2 \times$ to remove the loosely bound microreactors and fixed using a 4\% PFA solution in PBS for $30 \mathrm{~min}$. Next, the cells were washed in PBS $3 \times$. For staining, the cells were first permeabilized using T-PBS (0.1\% Triton X-100 in PBS) for $15 \mathrm{~min}$. 
A BSA solution (2\% BSA in PBS) for $2 \mathrm{~h}$ was used to block the nonspecific points. Incubation of the cells in a solution of phalloidin-TRITC $(0.1 \mu \mathrm{g} \mathrm{mL}-1$ in PBS $)$ for $1 \mathrm{~h}$ at RT in the dark was used to stain the actin filaments. The cells in the wells or in the channels were then washed $3 \times$ in PBS and imaged by CLSM (Leica Microsystems GmbH, Wetzlar, Germany). A DPSS 561 laser with emission/excitation wavelength 561/565-670 nm was used for phalloidin-TRITC detection while an Ar laser with emission/excitation wavelength 488/495-505 $\mathrm{nm}$ was employed for both $\mathrm{MR} \mathrm{L}_{\mathrm{TYR}}-\mathrm{PAH}^{\mathrm{F}}$ and MR3L $\mathrm{L}_{\mathrm{TYR}}$ detection. A $63 \times$ water immersion objective was employed.

2.19. Inhibition of Melanoma Cells Proliferation. For static conditions, B16-F10 and RAW 264.7 cells were seeded onto 96-well plates (static conditions) and to the channels of the microfluidic chamber (dynamic conditions). After $24 \mathrm{~h}$ incubation, the cells were washed in PBS $(2 \times)$ and $M R 3 L_{T Y R}$ at 50:1 microreactors-to-cell ratio were added to the wells and channels. For dynamic conditions, the syringes of the pump system (loaded with $7.5 \mathrm{~mL}$ of complete cell media) were connected to the channels. The Ibidi Pump System was used to apply two different controlled shear stresses $(\tau 0.5$ and $\tau 20)$. The cells were incubated for different time intervals (up to three days) at $37{ }^{\circ} \mathrm{C}$ and $5 \% \mathrm{CO}_{2}$. As controls, for both static and dynamic conditions, free TYR and cells without microreactors exposure were considered. Cells without microreactors exposure at $\tau 0$ was considered as the high control while medium only at $\tau 0$ was considered as the low control. After the different incubation times, the cells from both the wells and the channels were washed $2 \times$ in PBS $(200 \mu \mathrm{L}$ for wells and $100 \mu \mathrm{L}$ for channels) and $1 \times$ in fresh DMEM $(90 \mu \mathrm{L}$ for both wells and channels) containing PrestoBlue ${ }^{\circledR}$ cell viability reagent $(10 \mu \mathrm{L}$ for both wells and channels). Next, fresh DMEM (90 $\mu \mathrm{L}$ for both wells and channels) containing PrestoBlue ${ }^{\circ}$ cell viability reagent (10 $\mu \mathrm{L}$ for wells and channels) was added to the different wells/channels and incubated for $1 \mathrm{~h}$ at $37^{\circ} \mathrm{C}$ in the dark. The fluorescence intensity of the reduced resazurin product 
was assessed at excitation/emission wavelength of 535/615 $\mathrm{nm}$ using the multimodal plate reader. The normalized cell viability was calculated as follows: normalized cell viability (\%) $=($ experimental value - low control value $) /($ high control value - low control value $) \times 100$.

2.20. Statistics. A Tukey's multiple comparison posthoc test $\left(\mathrm{n}=3 ;{ }^{*} \mathrm{p} \leq 0.05 ; * * \mathrm{p} \leq 0.01 ;{ }^{* *} \mathrm{p} \leq\right.$ $0.001 ; * * * * \mathrm{p} \leq 0.0001$ ) was employed using a GraphPad Prism 7 software to assess the statistical differences between the different conditions. A one-way ANOVA with a confidence level of $95 \%$ $(\alpha=0.05)$ was employed.

\section{RESULTS AND DISCUSSION}

3.1. Enzymatic Conversion Using Free TYR in Solution. As a first step, we aimed to illustrate that the activity of the enzymatic reaction could be monitored. TYR catalyzes the conversion of Ltyr into melanin by a series of reactions (Figure S1, Supporting Information). ${ }^{42}$ To this end, we incubated different amounts of TYR in a L-tyr solution $(0.66 \mathrm{mM}$ in PBS $)$ at $37^{\circ} \mathrm{C}$ and quantified the amount of melanin formed at different time-points. The melanin precipitate was dissolved and the absorbance of the disintegrated product was measured at $475 \mathrm{~nm}$ (Figure S2a, Supporting Information). ${ }^{43,44}$ Our ultimate goal is to conduct the enzymatic conversion of L-tyr in the presence of melanoma cells. Therefore, we also monitored the kinetics of the TYR reaction in Dulbecco's Modified Eagle's Medium (DMEM) without the addition of phenol red. As expected, no differences in the kinetics of the enzymatic reaction were observed (Figure S2b, Supporting Information).

3.2. Assembly Optimization for TYR-Loaded Microreactors. 3.2.1. Liposomes Assembly and Characterization. The first step to assemble advanced microreactors involves enzyme encapsulation within liposomes. Liposomes are excellent candidates to entrap delicate biomolecules such as enzymes, preventing them from denaturation, by means of their lipid bilayer 
membrane which resembles the membrane of biological cells. ${ }^{37,38}$ Since our multicompartment microreactors have as a goal depleting L-tyr inside the human body, we assembled TYR-loaded liposomes $\left(\mathrm{L}_{\mathrm{TYR}}\right)$ that operate close to physiological temperature $\left(\sim 37^{\circ} \mathrm{C}\right)$. As such, $\mathrm{L}_{\mathrm{TYR}}$ were constituted by a lipid mixture displaying a liquid-to-gel phase transition temperature $\left(T_{\mathrm{m}}\right)$ close to $37{ }^{\circ} \mathrm{C}$. In particular, we employed 1,2-dimyristoyl-sn-glycero-3-phosphocholine (DMPC, $T_{\mathrm{m}} \sim 24$ ${ }^{0} \mathrm{C}$ ) and 1,2-dipalmitoyl-sn-glycero-3-phosphocholine (DPPC, $T_{\mathrm{m}} \sim 41{ }^{\circ} \mathrm{C}$ ) in a 7:3 weight ratio. At low temperatures such as room temperature (RT, $\sim 23{ }^{\circ} \mathrm{C}<T_{\mathrm{m}}$ ), $\mathrm{L}_{\mathrm{TYR}}$ offer an effective barrier for small molecules while, upon rising the temperature to or above the $T_{\mathrm{m}}$, L-tyr can permeate through the lipid bilayer and interact with the entrapped TYR enzyme (Scheme 1a). Following on, to fabricate microreactors with high enzymatic activity, we evaluated the highest amount of TYR that could be encapsulated or associated with the liposomes. We assembled $\mathrm{L}_{\mathrm{TYR}}$ by hydrating the lipid film with different amounts of TYR. After removing the non-encapsulated/associated TYR by dialysis, the total amount of TYR was evaluated by rupturing the liposomes with Triton-X followed by a bicinchoninic acid (BCA) assay. Figure 1a shows a maximum experimental TYR concentration of $\sim 750 \mu \mathrm{g} \mathrm{mL}^{-1}$ (or $2015 \mathrm{U}$ ) when $\mathrm{L}_{\mathrm{TYR}}$ are constituted by $2.5 \mathrm{mg} \mathrm{mL}^{-1}$ lipids. This loading was achieved when hydrating the lipid film with $1 \mathrm{~mL}$ of a $1116 \mu \mathrm{g} \mathrm{mL}^{-1} \mathrm{TYR}$ solution in (4-(2-hydroxyethyl)-1-piperazineethanesulfonic acid) (HEPES) buffer. $\mathrm{L}_{\text {TYR }}$ had a diameter of $166.6 \pm 6.4 \mathrm{~nm}$ and a surface charge of $-21.4 \pm 2.9 \mathrm{mV}$, respectively, as shown by dynamic light

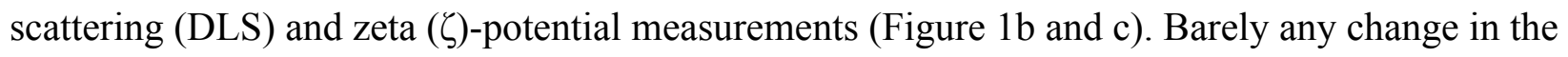
liposomes diameter was observed for $\mathrm{L}_{\mathrm{TYR}} v s$ empty $\mathrm{L}$. In contrast, an increase in negative $\zeta$ potential is observed for $\mathrm{L}_{\text {TYR }}$ upon increasing the TYR concentration (until reaching saturation conditions), which we attribute to the negatively charged nature of TYR at physiological $\mathrm{pH}$ (Figure 1c). 
To discern between the amount of TYR encapsulated from the TYR associated with the liposomes membrane, we evaluated the enzymatic conversion at temperatures below $\left(4{ }^{\circ} \mathrm{C}\right)$ and above $(42$ ${ }^{\circ} \mathrm{C}$ ) the $T_{\mathrm{m}}$ of the liposomes. At $4{ }^{\circ} \mathrm{C}$ the liposomes membrane is in the "gel state" and, thus, L-tyr can only react with the TYR enzyme attached to the liposomes membrane. In contrast, at $42{ }^{\circ} \mathrm{C}$ the liposomes membrane is in the "liquid state" making possible for L-tyr to cross the lipid bilayer and interact with the entrapped TYR. The enzymatic kinetics, which have been normalized to the highest absorbance reading, were conducted until a reaction end point was reached for at least three days. The results suggest $\sim 40 \%$ of TYR encapsulation (Figure 1d). It is worth noticing that no difference in TYR kinetics was observed when the enzymatic reaction was conducted for the free TYR at different temperatures (Figure S3, Supporting Information).

\subsubsection{Optimization of Microreactors Assembly. As an advanced microreactor able to deplete L-tyr}

in the intra-tumor environment, we chose a multicompartment carrier composed by intact liposomes entrapped within a protective polymeric shell. We, ${ }^{36,45}$ and others, ${ }^{46-48}$ have reported the assembly of such a multicompartment carrier based on the layer-by-layer (LbL) technique. The LbL technique entails the alternating deposition of interacting compounds (e.g., polymers and liposomes) onto a (sacrificial) core. Those microreactors have been mainly assembled by employing silica particles as a (sacrificial) core template and either biodegradable disulfide crosslinked poly(methacrylate) $)^{36,45}$ or polydopamine ${ }^{35,46-50}$ as the constituents of the carrier shell. In contrast, herein, with the aim to obtain microreactors that are able to conduct their function for an extended period of time, we employ a non-degradable polymer pair. To construct the carrier shell we make use of poly(allylamine hydrochloride) (PAH) and poly(styrene sulfonate) (PSS) which interact by electrostatics (Schematic 2). ${ }^{32}$ Additionally, since our goal is to fabricate an extracellularly active microreactor, to minimize or even eliminate the microreactors uptake by 
melanoma cells, we assembled microreactors without removing the core template. With that in mind, we chose as a core micron-sized biocompatible poly(D,L-lactide-co-glycolide) (PLGA) microspheres fabricated by a double emulsion process. ${ }^{41}$ The as-prepared PLGA microspheres displayed a size ranging from 1 to $9 \mu \mathrm{m}$ in diameter with the highest amount of microspheres exhibiting a diameter between 3 to $6 \mu \mathrm{m}$. As shown by scanning electron microscopy (SEM) images (Figure S4, Supporting Information) the microspheres display a uniform, smooth structure without the presence of large pores. Next, we assembled the microreactors by depositing alternate layers of PAH, PSS and $\mathrm{L}_{\mathrm{TYR}}$. The combination of PSS and PAH was chosen to assemble the polymeric shell since this polymer pair is widely known to yield non-aggregated and structurally stable particles and capsules. ${ }^{51,52}$ Additionally, the non-degradable nature of this polymer pair will render microreactors with good structural integrity for prolonged time periods.

To optimize the microreactors assembly, we first characterized the adsorption of $\mathrm{L}_{\mathrm{TYR}}$ onto PLGA microspheres. To render a positively charged surface that allows for $\mathrm{L}_{\mathrm{TYR}}$ immobilization, the PLGA microspheres were first coated by a PAH layer. We first established the amount of PAH needed to revert the charge of the PLGA microspheres. We monitored the $\zeta$-potentials of the microspheres upon incubation with different PAH concentrations for different time intervals. As expected, the higher the PAH concentration, the higher the $\zeta$-potentials until saturation was reached for a $40 \mathrm{mg} \mathrm{mL}^{-1} \mathrm{PAH}$ solution (Figure 2a). An additional increase in PAH concentration did not translate into a notable increase in $\zeta$-potential. Following on, after $\mathrm{L}_{\mathrm{TYR}}$ deposition, we optimized the LbL growth for a polymeric shell constituted by PAH and PSS. PSS and PAH were chosen due to prior history in yielding non-aggregated and structurally stable particles and capsules. ${ }^{51,52}$ We monitored the $\zeta$-potential of the microspheres as a function of both the number of PAH and PSS layers and their concentrations (Figure 2b). Upon deposition of a PAH precursor 
layer, the $\zeta$-potential of the PLGA microspheres increased by $\sim 85 \mathrm{mV}$. We attribute this sharp increase in $\zeta$-potential to the porous nature of the PLGA microspheres. When $\mathrm{L}_{\mathrm{TYR}}$ were adsorbed, a $\sim 60 \mathrm{mV}$ decrease in $\zeta$-potential was observed due to the overall negative charge of $\mathrm{L}_{\text {TYR }}$. Next, $4 \mathrm{mg} \mathrm{mL}^{-1}$ concentrations of both PAH and PSS were employed to assemble the shell of the multicompartment carrier. The $\zeta$-potential of the microspheres alternated between $+5 \mathrm{mV}$ and -60 $\mathrm{mV}$ when PAH and PSS formed the outer layer, respectively (Figure 2bi). Such a switch in the sign of the $\zeta$-potential are distinctive of the LbL formation of multilayers on colloids and suggest a step-wise layer growth of PAH and PSS. ${ }^{53}$ We next aimed to obtain $\zeta$-potential measurements closer to the values that are usually obtained for PAH and PSS $(\sim+30 \mathrm{mV}$ and $\sim-20 \mathrm{mV}$ for PAH and PSS as outermost layer, respectively). ${ }^{54}$ Thus, we assessed the $\zeta$-potential of the coated-PLGA microspheres for different PAH and PSS concentrations. We first decreased the PSS concentration to $1 \mathrm{mg} \mathrm{mL}^{-1}$ while maintaining the PAH concentration constant $\left(4 \mathrm{mg} \mathrm{mL}^{-1}\right)$. This resulted in a $\zeta$ potential alternating between $\sim+2-3 \mathrm{mV}$ and $\sim-40 \mathrm{mV}$ for PAH and PSS as the outer layer, respectively (Figure 2bii). Next, to achieve a higher $\zeta$-potential upon PAH deposition, we increased the PAH concentration to $8 \mathrm{mg} \mathrm{mL}^{-1}$. The results show $\zeta$-potential measurements ranging from $\sim+30 \mathrm{mV}$ to $\sim-30 \mathrm{mV}$, which are values closer to the ones reported in literature,,${ }^{54}$ thus promoting a good surface coverage (Figure 2biii).

Next, to maximize the number of liposomal compartments and consequently the quantity of entrapped TYR, we identified the upper limit of liposome multi-layering onto PAH-coated PLGA microspheres. We monitored the adsorption of fluorescently labelled $\mathrm{L}_{\mathrm{TYR}}\left(\mathrm{L}_{\mathrm{TYR}}\right)$ onto PAHcoated PLGA microspheres by flow cytometry. Figure 3 shows fluorescence intensity (FI) readings for PAH and $\mathrm{L}^{\mathrm{F}} \mathrm{TYR}$ deposition onto PLGA microspheres. The readings are normalized to the first $\mathrm{L}^{\mathrm{F}}$ TYR deposition step ( $\mathrm{nFI}$ ), which was set to $100 \%$ and assigned as a single liposome 
layer. After the first $\mathrm{L}^{\mathrm{F}}{ }_{\mathrm{TYR}}$ deposition step, to allow for the adsorption of a second $\mathrm{L}^{\mathrm{F}} \mathrm{TYR}$ layer, the deposition of a separation polymer layer is required. To reverse the charge of the coated microspheres, positively charged PAH was adsorbed. This PAH separation layer between $\mathrm{L}^{\mathrm{F}}$ TYR supported the addition of three extra $\mathrm{L}^{\mathrm{F}}{ }_{\mathrm{TYR}}$ deposition steps. While the second deposition step allowed for the adsorption of $\sim 2.5 \mathrm{~L}^{\mathrm{F}} \mathrm{TYR}$ layers, the third and fourth liposome deposition steps supported the addition of almost 3 and $\sim 1.2 \mathrm{~L}^{\mathrm{F}} \mathrm{TYR}$ layers, respectively. After four liposome deposition steps, any additional exposure of the colloids to $\mathrm{L}^{\mathrm{F}}{ }_{\mathrm{TYR}}$ promoted aggregation of the coated microspheres. The stability of $\mathrm{L}^{\mathrm{F}} \mathrm{TYR}$ during subsequent carrier shell assembly was also investigated for the four different scenarios (i.e., one, two, three and four $\mathrm{L}^{\mathrm{F}} \mathrm{TYR}$ deposition steps). The FI readings, which have been normalized to the first $\mathrm{L}^{\mathrm{F}}{ }_{\mathrm{TYR}}$ deposition step, show no notable loss in nFI during subsequent PAH/PSS layering for any of the tested conditions (Figure 4a i-iv). The microreactors assembled with different $\mathrm{L}^{\mathrm{F}} \mathrm{TYR}$ deposition steps were visualized using differential interference contrast (DIC) and fluorescence microscopy to corroborate and analyze their appearance and structural integrity (Figure 4b). Fluorescence microscopy images showed that the $\mathrm{L}^{\mathrm{F}}$ TYR were homogeneously distributed around the PLGA microspheres as shown by the homogeneous fluorescence signal. They also confirmed the presence of additional $\mathrm{L}^{\mathrm{F}}{ }_{\mathrm{TYR}}$ layers for microreactors assembled by increasing number of liposome deposition steps, as shown by the increasing fluorescence intensity signal. The microscopy images also demonstrated that, while microreactors prepared by one, two or three $\mathrm{L}^{\mathrm{F}}{ }_{\mathrm{TYR}}$ deposition steps where intact and nonagglomerated, the microspheres aggregated for microreactors with four $\mathrm{L}^{\mathrm{F}} \mathrm{TYR}_{\mathrm{R}}$-deposition steps (Figure S5, Supporting Information, shows enlarged microscopy images). Hence, only microspheres loaded with three $\mathrm{L}^{\mathrm{F}}{ }_{\mathrm{TYR}}$ deposition steps $\left(\mathrm{MR}^{3} \mathrm{~L}_{\mathrm{TYR}}\right.$ ) where considered for the next experiments. 
Despite the encouraging results, the flow cytometry data together with the fluorescence microscopy images, only proved the presence of fluorescently labelled lipids linked to the microspheres. Only the combination with quartz crystal microbalance with dissipation monitoring (QCM-D) measurements will verify the presence of structurally intact $\mathrm{L}_{\mathrm{TYR}}$ (Figure 5). In good agreement with the data attained by flow cytometry on PLGA microspheres, the adsorption of PAH precursor polymer layer onto gold sensors was corroborated by assessing the change of frequency $(\Delta \mathrm{f})$ of $-6.55 \pm 0.25 \mathrm{~Hz}$. This positively charged surface allowed for the adsorption of negatively charged $\mathrm{L}_{\mathrm{TYR}}$ as shown by the $\Delta \mathrm{f}$ of $-111.71 \pm 22.01 \mathrm{~Hz}$. The change in dissipation $(\Delta \mathrm{D})$ of $30.90 \times 10^{6} \pm 9.32 \times 10^{6}$, suggests the deposition of intact liposomes rather than a supported lipid bilayer. ${ }^{55} \mathrm{Next}$, a PAH separation layer, as confirmed by a $\Delta$ f of $-18.38 \pm 6.50 \mathrm{~Hz}$, was adsorbed to allow for the deposition of additional $\mathrm{L}_{\mathrm{TYR}}$. The successful deposition of intact liposomes was also confirmed by the large $\Delta \mathrm{f}$ and $\Delta \mathrm{D}$ (of $-71.86 \pm 1.00 \mathrm{~Hz}$ and $28.66 \times 10^{6} \pm 0.91$ $\times 10^{6}$ for $\Delta \mathrm{f}$ and $\Delta \mathrm{D}$, respectively). After addition of the second PAH separation layer ( $\Delta \mathrm{f}$ of $18.21 \pm 2.54 \mathrm{~Hz}$ ) a third deposition step of intact $\mathrm{L}_{\mathrm{TYR}}$ was successfully adsorbed as shown by a $\Delta \mathrm{f}$ of $-123.25 \pm 19.21 \mathrm{~Hz}$ and $\mathrm{a} \Delta \mathrm{D}$ of $29.56 \times 10^{6} \pm 1.78 \times 10^{6}$, which again are in the envisioned range for the incorporation of intact liposomes. The adsorption of PAH and PSS to assemble the microreactors shell was corroborated without rupture or rearrangement of the underlying liposomes as shown by the film growth $\left(\mathrm{PAH}, \Delta \mathrm{f}\right.$ of $-29.72 \pm 8.92 \mathrm{~Hz}$ and $\Delta \mathrm{D}$ of $6.84 \times 10^{6} \pm 2.30$ $\times 10^{6} ; \mathrm{PSS}, \Delta \mathrm{f}$ of $-25.46 \pm 3.24 \mathrm{~Hz}$ and $\Delta \mathrm{D}$ of $\left.9.73 \times 10^{6} \pm 6.43 \times 10^{6}\right)$.

3.3. Microreactors Functionality. 3.3.1. Kinetics of the Enzymatic Reaction. To evaluate the MR3L $_{\text {TYR }}$ 's potential as an intra-tumor microreactor for the depletion of L-tyr, we incubated

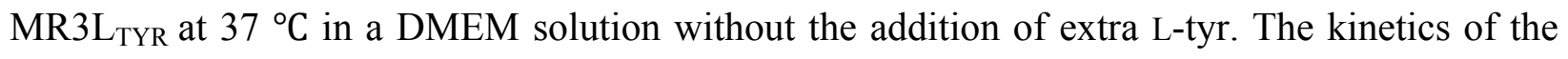
enzymatic conversion of L-tyr by MR3 $\mathrm{L}_{\mathrm{TYR}}$ were normalized to the highest absorbance reading 
(nAbsorbance). The kinetics of $\mathrm{MR} 3 \mathrm{~L}_{\mathrm{TYR}}$ at $37{ }^{\circ} \mathrm{C}$ were compared to the kinetics of $\mathrm{MR} 3 \mathrm{~L}_{\mathrm{TYR}}$ at RT, same amounts of TYR enzyme in its free form (as determined by a calibration curve), empty microreactors (MR3L) and DMEM only. Enzymatic conversion was only observed for MR3L $\mathrm{L}_{\mathrm{TYR}}$ and free TYR, where the absorbance measurements steadily increased for the first hours levelling off after one day of reaction (Figure 6a). While, for both $\mathrm{MR} 3 \mathrm{~L}_{\mathrm{TYR}}$ at $37^{\circ} \mathrm{C}$ and free $\mathrm{TYR}$ (at $37^{\circ} \mathrm{C}$ and RT), the enzymatic processes took place at a similar rate, the results were different for

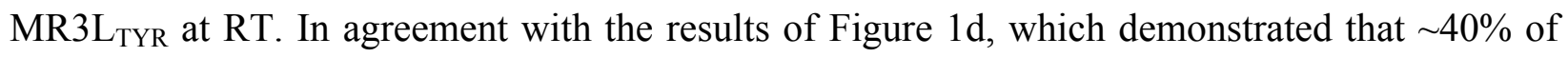
TYR was encapsulated inside $\mathrm{L}_{\mathrm{TYR}}$, the $\mathrm{nAbsorbance}$ readings for MR3 $\mathrm{L}_{\mathrm{TYR}}$ at $\mathrm{RT}$ are $\sim 40 \%$ lower

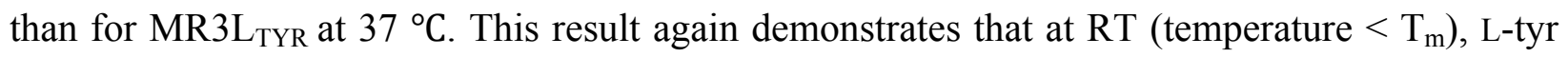
can only react with the TYR enzyme associated with the liposomes surface. All in all, these results confirm the preserved activity of the microreactors and that $\sim 40 \%$ of the enzyme is entrapped within intact liposomes.

3.3.2. Repeated Enzymatic Conversion. We, ${ }^{35,36,45}$ and others, ${ }^{56}$ have previously demonstrated that microreactors based on a polymer carrier shell encapsulating liposomes are able to handle successive enzymatic reactions within their liposomal subunits. This is a crucial aspect, since it is expected that, once administered into the body, the microreactors will able to convert molecules in a continuous and sustained manner. Enzymes are not only challenging and costly to obtain in a highly-purified form suitable for human use but it is also advantageous for patients' compliance to minimize the amount of doses to be administered. As such, to confirm that the TYR enzyme within $M R 3 L_{T Y R}$ could be reused, we repeated the enzymatic conversion by exchanging the melanin product by fresh DMEM over multiple rounds. The results, which were normalized to the absorbance reading at $475 \mathrm{~nm}$ monitored after the initial reaction at $37{ }^{\circ} \mathrm{C}$, showed that the enzymatic conversion was reduced by $10 \%, 50 \%$ and $60 \%$ between each subsequent cycle, 
respectively (Figure 6bi). Nonetheless, it was still possible to measure enzymatic activity even after four cycles of enzymatic reaction. This shows $M R 3 \mathrm{~L}_{\mathrm{TYR}}$ to be a robust platform able to conduct several reaction cycles, even after being exposed to spinning and resuspension treatment for multiple rounds. Figure 6bii shows that, although slightly aggregated, MR3 $L_{T Y R}$ preserve their structural integrity after the four rounds of spinning/resuspension.

3.4. Microreactors Interaction with Melanoma Cells. Biocompatibility of microreactors consisting of a polymeric shell entrapping thousands of liposomes has been previously reported by several research groups including ours in several cell lines. ${ }^{35,36,45,48,57}$ Since, in order to deplete L-tyr from the intra-tumor environment, $\mathrm{MR} 3 \mathrm{~L}_{\mathrm{TYR}}$ will have to avoid cell internalization, we assessed the interaction of pristine MR3L in terms of cell viability (CV) and cell internalization by the mouse melanoma cell line B16-F10 and macrophage RAW 264.7 cell lines. The mouse macrophage RAW 264.7 cell line was chosen due to the relevance of macrophages as the first defense line of the human body against invading microorganisms. Macrophages will be also circulating in the blood vessels at the melanoma tumor site.

\subsubsection{Microreactors Biocompatibility. We first evaluated the CV of both B16-F10 and RAW} 264.7 cells exposed to empty MR3L at two different microreactors-to-cell ratios (50:1 and 100:1) for up to five days. The CV readings, which were normalized to untreated cells (nCV), showed that no significant decrease in $\mathrm{nCV}$ for B16-F10 for neither 50:1 or 100:1 microreactors-to-cell ratios at all the studied time-points (Figure S6a, Supporting Information). In contrast, a significant decrease in nCV was observed when RAW 264.7 cells were exposed to a 100:1 microreactors-tocell ratio for all the studied time-points (Figure S6b, Supporting Information). Thus, to avoid any potential cytotoxicity, we decided to conduct the following experiments employing a 50:1 microreactors-to-cell ratio. 


\subsubsection{Microreactors Association with Melanoma Cells. The assembly of microreactors with} demonstrated activity in a test tube has impressively advanced and, in recent years, many examples of progressive functionality have been reported as recently reviewed..$^{21-23,58}$ However, it has been only recently that the interaction of such microreactors with cells has started to be explored. A first approach was reported by Hammond and co-workers by co-culturing microbeads and insulinsecreting pancreatic $\beta$-cells to enhance the cells function and survival. ${ }^{59}$ Further progress in the field has been conducted by Städler and co-workers by illustrating the ability of extracellular microreactors to remove reactive oxygen species in the presence of damaged hepatocytes ${ }^{46}$ or neuroblastoma cells. ${ }^{60}$

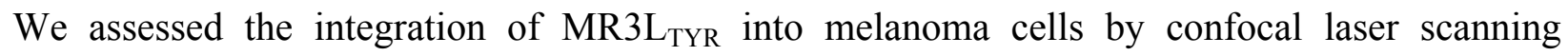
microscopy (CLSM) (Figure 7). In order to image the microreactors, fluorescently labelled PAH $\left(\mathrm{PAH}^{\mathrm{F}}\right)$ was used for the MR3 $\mathrm{L}_{\mathrm{TYR}}$ assembly $\left(\mathrm{MR} 3 \mathrm{~L}_{\mathrm{TYR}}-\mathrm{PAH} \mathrm{H}^{\mathrm{F}}\right)$. The $\mathrm{MR} 3 \mathrm{~L}_{\mathrm{TYR}}-\mathrm{PAH}^{\mathrm{F}}$ were then incubated with B16-F10 melanoma cells for up to five days. After the different incubation times, the cells were fixed, their actin filaments stained and imaged by CLSM. As expected, due to their

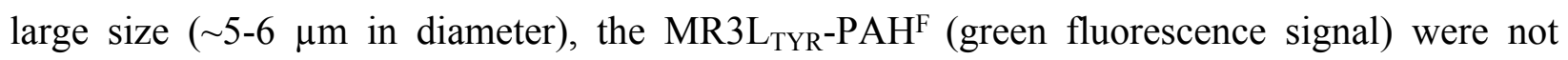
internalized by the melanoma cells (red fluorescence signal) (Figure 7b). Importantly, and as previously shown by the CV assays, healthy looking melanoma cells could be observed at all the studied time-points. We also assessed the integrity of the liposomal compartments at different time-points for the whole five-day period. To this end, the microreactors were fabricated employing $\mathrm{L}^{\mathrm{F}}{ }_{\text {TYR }}$ yielding MR3 $\mathrm{L}^{\mathrm{F}}$ TYR. After the different incubation times, the cells were stained, fixed and visualized by CLSM. Upon incubating MR3 $\mathrm{L}^{\mathrm{F}}{ }_{\mathrm{TYR}}$ for one to three days, homogeneously distributed green fluorescence signal along the microreactors shell could be observed (Figure 7c). Those results potentially indicate a relatively stable liposome membrane protecting the entrapped 
enzyme. In contrast, after four and five days of incubation, the green fluorescence signal was distributed throughout the microreactors. This suggests either the leakage of the fluorescent lipid form $\mathrm{L}^{\mathrm{F}}$ TYR or $\mathrm{L}^{\mathrm{F}}$ TYR fusion or rearrangement. ${ }^{61}$ Since liposomes integrity is a central factor for the microreactors performance, $\mathrm{MR} 3 \mathrm{~L}^{\mathrm{F}}{ }_{\mathrm{TYR}}$ functionality in the presence of melanoma cells will be assessed for up to three days.

3.5. Microreactors Activity to Inhibit Melanoma Cells Proliferation. To evaluate the potential of the as-prepared microreactors towards melanoma treatment, we next examined the ability of MR3L $_{\text {TYR }}$ in inhibiting B16-F10 melanoma cell growth in culture. We incubated B16-F10 melanoma cells with MR3 $\mathrm{L}_{\mathrm{TYR}}$ and free TYR and monitored the $\mathrm{nCV}$ after 1, 2 and 3 days, respectively (Figure 8). When incubating the cells with same units of TYR as encapsulated within the MR3 $\mathrm{L}_{\mathrm{TYR}}$ but in its free form, only a $\sim 20 \%$ decrease in $\mathrm{nCV}$ was observed for the three timepoints. However, the results were different for cells incubated with MR3 $\mathrm{L}_{\text {TYR }}$. While only $\sim 10 \%$ decrease in $\mathrm{nCV}$ was observed after 1 day; 2 and 3 days of incubation decreased the $\mathrm{nCV}$ by $\sim 35$ and $\sim 50 \%$, respectively. The different results obtained for the free TYR and TYR within MR3 $\mathrm{L}_{T Y R}$ could be explained by the fast degradation of the TYR enzyme by proteases of the cell medium. This highlights the importance of an encapsulation platform to protect the enzyme, which is an important fact for our envisioned application, since proteases are implicated in tumor progression, angiogenesis, invasion and metastasis. ${ }^{39,62}$ The decrease in $\mathrm{nCV}$ when employing microreactors suggest that $M R 3 \mathrm{~L}_{\mathrm{TYR}}$, by means of their semipermeable nature, are able to deplete L-tyr. Next, we also evaluated the effect of both free TYR and MR3 $\mathrm{L}_{\mathrm{TYR}}$ on the $\mathrm{nCV}$ of RAW 264.7 (a model non-L-tyr-dependent cell line). Figure $8 \mathrm{~b}$ shows a significant decrease in $\mathrm{nCV}$ upon incubating both the free TYR and MR3L $\mathrm{L}_{\text {TYR }}$ with RAW 264.7 cells for all three time-points. However, this decrease in $\mathrm{nCV}$ was lower ( $\sim 20 \%$ decrease in $\mathrm{nCV}$ for the all the time-points) as compared to the 
decrease in nCV for B16-F10 cells ( $\sim 35 \%$ and $\sim 50 \%$ decrease for two and three days incubation time, respectively). Although in recent years many examples of microreactors conducting enzymatic reactions in the presence of cells have been published by us ${ }^{35,36,45}$ and others, ${ }^{46,48,60,63,64}$ this is the first report where the depletion/conversion of a substrate into a product by an enzymatic microreactor is translated into anti-tumor properties.

3.6. Dynamic Intra-tumor Environment. Shear stress can influence important parameters such as the biocompatibility ${ }^{65}$ or cell interaction ${ }^{66}$ of a given carrier however, evaluating the effect of shear stress when characterizing a novel delivery system is often omitted. This fact could partly explain the deficient translation from in vitro static studies to in vivo models. ${ }^{67}$ Cancer cells also sense shear stress forces created by both the blood flow from the neighboring vascular microenvironment (with values ranging from 0.5 to $30.0 \mathrm{dyn}^{-2}$ ) as well as the interstitial flow

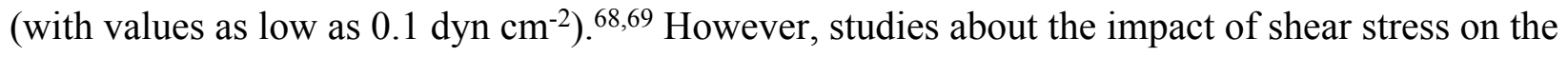
carriers interaction with cancer cells remain scarce. ${ }^{70}$ Herein, to better resemble the physiological environment that the microreactors will encounter in the tumor site, the ability of $M R 3 \mathrm{~L}_{\mathrm{TYR}}$ to prevent melanoma cells progression through L-tyr depletion was studied under the effect of two physiologically relevant shear stresses $\left(\tau=0.5 \mathrm{dyn} \mathrm{cm}^{-2}(\tau 0.5)\right.$ and $\left.\tau=20.0 \mathrm{dyn} \mathrm{cm}^{-2}(\tau 20)\right)$. We compared the results to the previously reported static conditions $(\tau 0)$. As such, we assessed the nCV of B16-F10 melanoma cells upon incubation with MR3 $\mathrm{L}_{\mathrm{TYR}}$ and free TYR by means of a microfluidic setup (Figure 9a). Both $\tau 0.5$ and $\tau 20$ were applied over the micro-channels. Figure $9 \mathrm{~b}$ shows $\mathrm{nCV}$ readings upon incubation of $\mathrm{MR} 3 \mathrm{~L}_{\mathrm{TYR}}$ at $\tau 0.5$ for one, two and three days (Figure 9 shows only the most relevant statistics, complete list of statistics can be found in Figure S7, Supporting Information). As controls, cells only, free TYR and empty MR3L were considered. As expected, ${ }^{66}$ neither $\tau 0.5$ nor $\tau 20$ did have a detrimental effect on nCV (Figure S8, Supporting 
Information). While, at $\tau 0.5$, the free TYR did not produce a significant decrease in $\mathrm{nCV}$, at $\tau 20 \mathrm{a}$ $\sim 10 \%$ decrease in $\mathrm{nCV}$ was observed for free TYR at all the studied time points (Figure $9 \mathrm{~b}$ and c). The higher values of nCV for free TYR at both $\tau 0.5$ and $\tau 20$ as compared to $\tau 0$, can be expected by the fact that the volume of medium in the microfluidic system $(\sim 6 \mathrm{~mL})$ is higher than the medium added in each well during static conditions $(\sim 200 \mu \mathrm{L})$. Importantly, this fact does not affect the MR3 $\mathrm{L}_{\mathrm{TYR}}$ since they remain associated with the cells due to their large size. In contrast, free TYR has been highly diluted in the microfluidic set up, thus reducing its ability to deplete Ltyr. Interestingly, no significant differences in the decrease in $\mathrm{nCV}$ can be observed when incubating MR3 $\mathrm{L}_{\text {TYR }}$ at $\tau 0.5$ and $\tau 20$ as compared to $\tau 0$. This results are of utmost interest since, as previously stated, the volume of medium in the microfluidic system is $\sim 30$ times higher than the medium added in each well during static conditions. Thus, although the L-tyr concentration is the same for dynamic and for static conditions, the total L-tyr amount is $\sim 30$ times higher for dynamic conditions. Therefore, those results highlight the enormous potential of $M R 3 \mathrm{~L}_{\mathrm{TYR}}$ to deplete L-tyr even at very high amounts, which is translated in a significant reduction in $\mathrm{nCV}$ for melanoma cells.

Finally, to verify that the MR3 $\mathrm{L}_{\mathrm{TYR}}$ microreactors were not internalized by cells and also, as an attempt to assess their integrity after the shear stress conditions, we assembled microreactors employing either $\mathrm{PAH}{ }^{\mathrm{F}}$ to create $\mathrm{MR} 3 \mathrm{~L}_{\mathrm{TYR}}-\mathrm{PAH}^{\mathrm{F}}$ or $\mathrm{L}^{\mathrm{F}}{ }_{\mathrm{TYR}}$ yielding $\mathrm{MR} 3 \mathrm{~L}^{\mathrm{F}} \mathrm{TYR}$, respectively. After incubation of MR $3 \mathrm{~L}_{\mathrm{TYR}}-\mathrm{PAH}{ }^{\mathrm{F}}$ for three days at either $\tau 0.5$ or $\tau 20$, the cells were stained, fixed and visualized by CLSM. Figure 10 a and $\mathbf{b}$ depict healthy looking melanoma cells after the shear stress conditions and upon being in contact with MR3 $\mathrm{L}_{\text {TYR }}$. When incubating MR3 $\mathrm{L}^{\mathrm{F}}{ }_{\text {TYR }}$ at either $\tau 0.5$ or $\tau 20$ for 3 days, the green fluorescence signal arising from $\mathrm{L}^{\mathrm{F}}{ }_{\mathrm{TYR}}$ was distributed throughout 
the microreactor indicating a potential leakage of the fluorescent lipid of fusion and rearrangement among the different $\mathrm{L}^{\mathrm{F}}$ TYR (Figure 10c).

\section{CONCLUSION}

To sum up, we have shown that liposome-containing microreactors are able to conduct enzymatic conversions in the presence of cells and under the effect of shear stresses resembling the dynamic environment of the tumour site. The depletion of the amino acid L-tyrosine by the microreactors inhibits melanoma cell growth in vitro. The results, therefore, represent an important step in the microreactors field since we have moved on from model enzymes to a medically relevant condition, i.e., slowing down melanoma progression. Further developments will include the assembly of microreactors with stabilized liposomes that can perform for extended periods of time (i.e., more than three days) and also with higher enzyme encapsulation efficiencies. Such stabilization could be performed either by coating the liposomes with polymer layers or by replacing them by polymersomes. Additionally, this multicompartment carrier will allow for the combination of enzyme therapy together with the co-encapsulation of small anti-tumour compounds to be loaded either in the liposomes or in the PLGA core.

Although many challenges still remain to be addressed, and the field of microreactors in biomedicine is still in its infancy, these highly advanced microreactors with multiple compartments may propose an alternative for future biomedical technologies. 


\section{FIGURES}

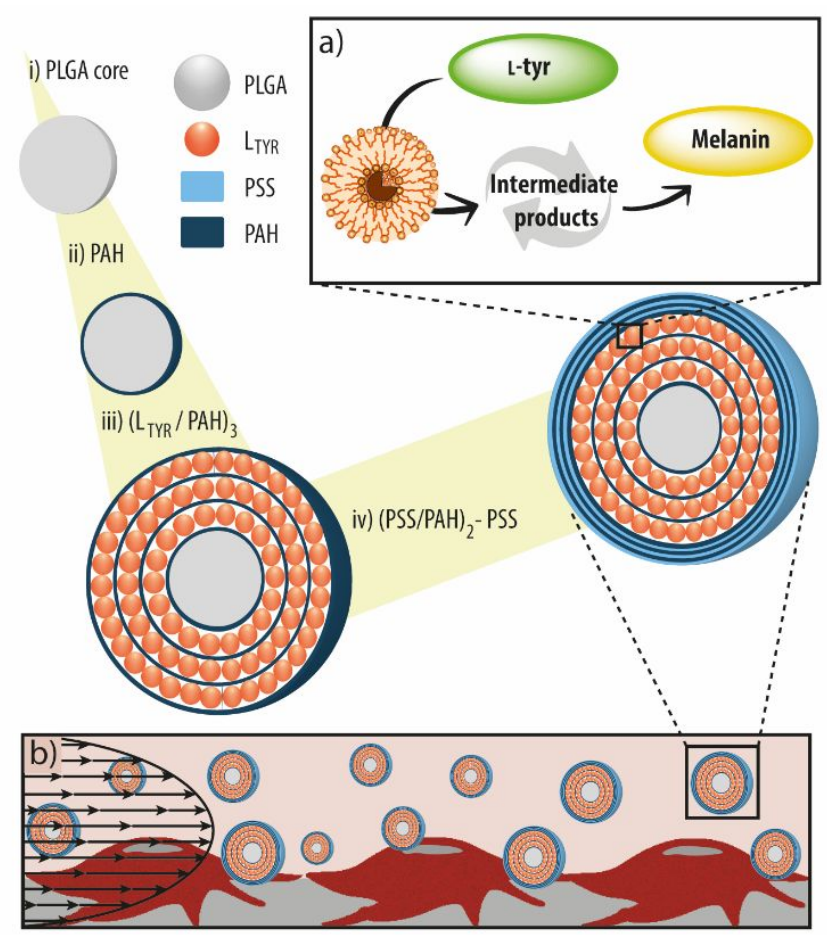

Scheme 1. Schematic illustration of the microreactors assembly. The assembly starts by a poly(D,L-lactic-co-glycolic acid) (PLGA) microsphere (i) coated by a poly(allylamine hydrochloride) (PAH) polymer precursor layer (ii) that allows for the deposition of tyrosinase (TYR)-loaded liposomes ( $\left.\mathrm{L}_{\mathrm{TYR}}\right)$. To allow for the deposition of another $\mathrm{L}_{\mathrm{TYR}}$ layer, a PAH separation layer is needed (iii). After a maximum of three $\mathrm{L}_{\mathrm{TYR}}$ deposition steps, the polymer carrier shell is constructed by the alternating deposition of poly(styrenesulfonic acid) (PSS) and PAH (iv). The assembly is terminated by a PSS layer and microreactors loaded with the TYR enzyme are obtained. a) The substrate L-tyrosine (L-tyr) is able to permeate through the liposomes membrane, interact with the encapsulated TYR enzyme and be converted into melanin by means of several intermediate products. b) The potential of the as-prepared microreactors to inhibit melanoma cells progression is evaluated in a microfluidic set up under the influence of intra-tumor shear stress. 

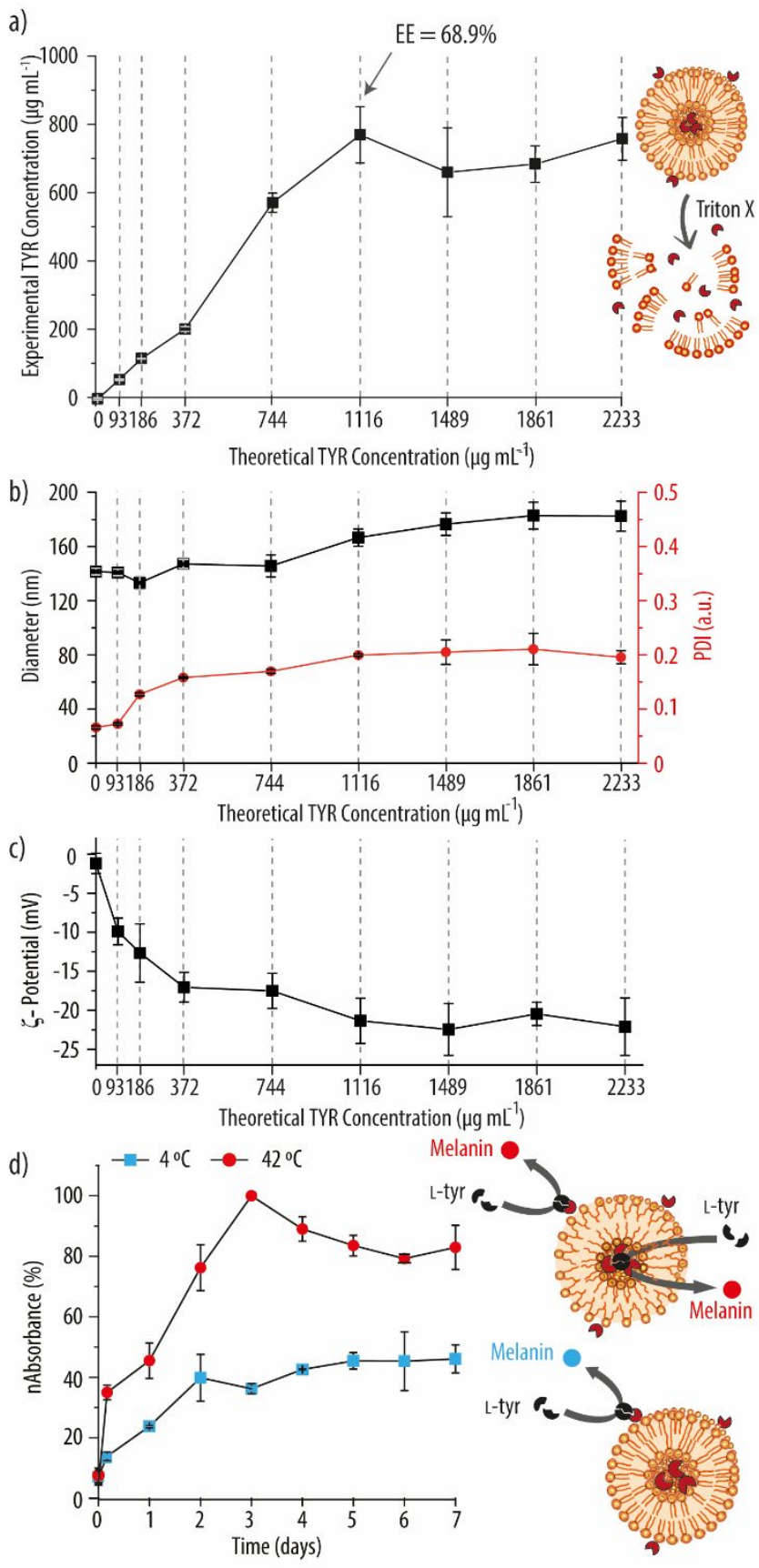

Figure 1. Enzyme encapsulation within liposomes. a) Liposomes encapsulating different amounts of tyrosinase (TYR) are destroyed by adding Triton $\mathrm{X}$ and the experimental concentration of TYR is assessed by a bicinchoninic acid (BCA) assay. The encapsulation efficiency (EE) of the liposomes encapsulating the highest TYR amount is calculated. b) The diameter and polydispersity (PDI) of liposomes encapsulating different amounts of TYR is determined by dynamic light 
2

3

4

5

6

7

8

9

10

11

12

13

14

15

16

17

18

19

20

21

22

23

24

25

26

27

28

29

30

31

32

33

34

35

36

37

38

39

40

41

42

43

44

45

46

47

48

49

50

51

52

53

54

55

56

57

58

59

60

scattering measurements. c) Zeta ( ()-potential measurements of liposomes loaded with increasing amounts of TYR. d) Normalized absorbance (nAbsorbance) readings measuring the conversion of L-tyrosine (L-tyr) into melanin by TYR encapsulated within liposomes at two different temperatures. 


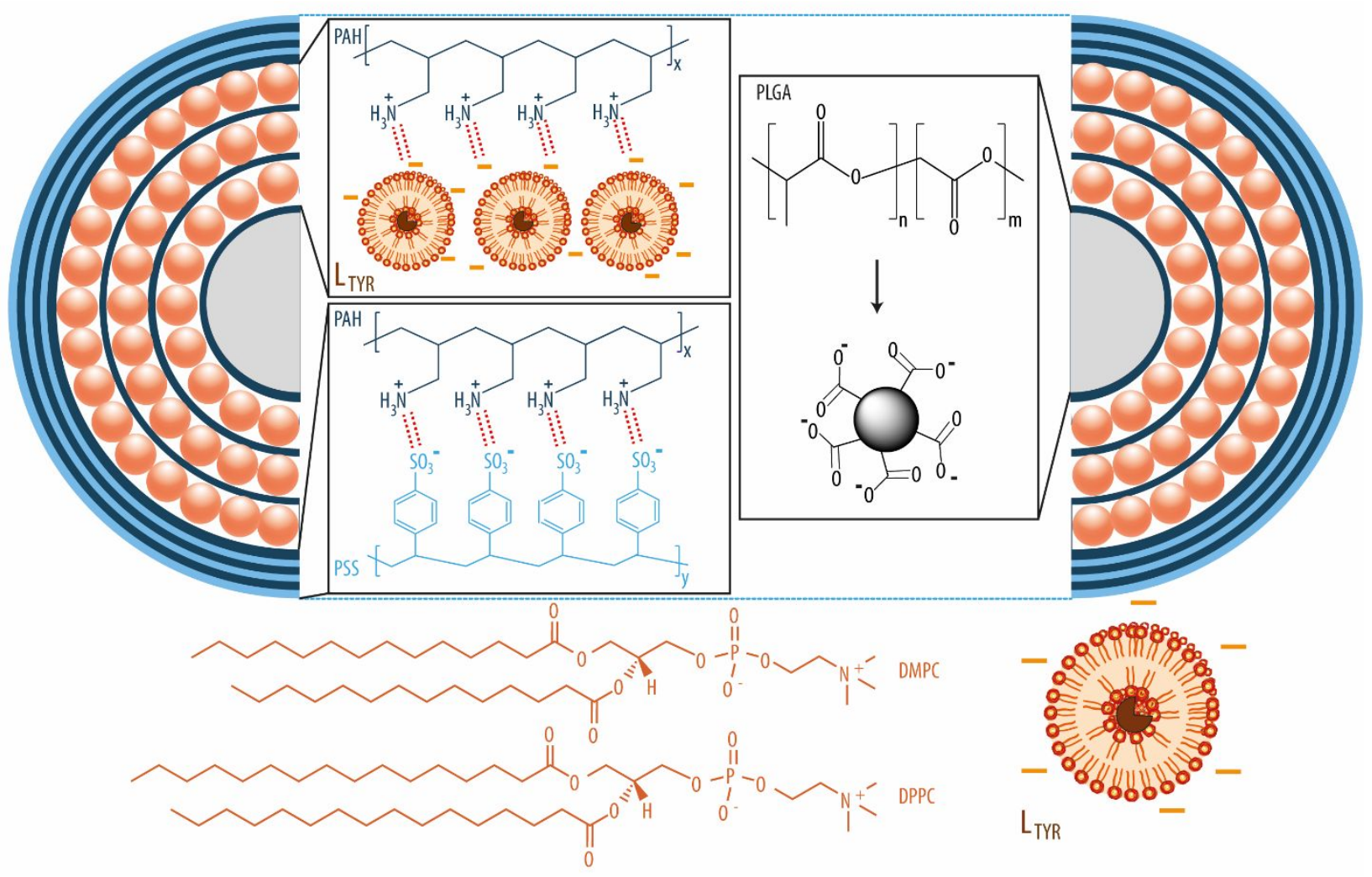

Scheme 2. Schematic illustration of tyrosinase (TYR)-loaded microreactors including the chemical structures of the relevant compounds. Micron-sized poly(D,L-lactide-co-glycolide) (PLGA) microspheres are first coated with poly(allylamine hydrochloride) (PAH) to render a positively charged surface that allows for the deposition of TYR-loaded liposomes $\left(\mathrm{L}_{\mathrm{TYR}}\right)$. To allow for the deposition of a second and a third $\mathrm{L}_{\mathrm{TYR}}$ layers, a separation PAH layer is needed. Following on, the carrier shell is assembled by the subsequent adsorption of poly(styrene sulfonate) (PSS) and PAH polymer layers which interact by electrostatics. 

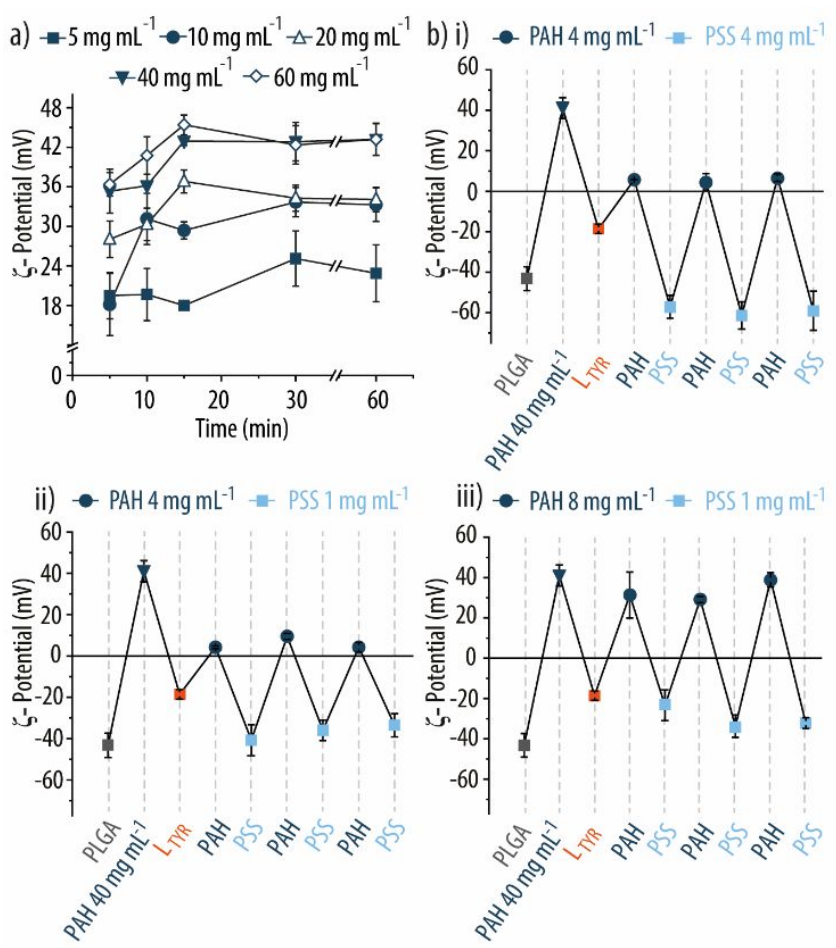

Figure 2. Characterization of the microreactors assembly. a) Zeta $(\zeta)$-potential measurements measured after incubating poly(D,L-lactic-co-glycolic acid) (PLGA) microspheres with increasing amounts of poly(allylamine hydrochloride) (PAH) over time. b) $\zeta$-potential of the PLGA microspheres measured after the different polymer and tyrosinase-loaded liposomes $\left(\mathrm{L}_{\mathrm{TYR}}\right)$ coating steps. Different concentrations of PAH and poly(styrenesulfonic acid) (PSS) are employed. 


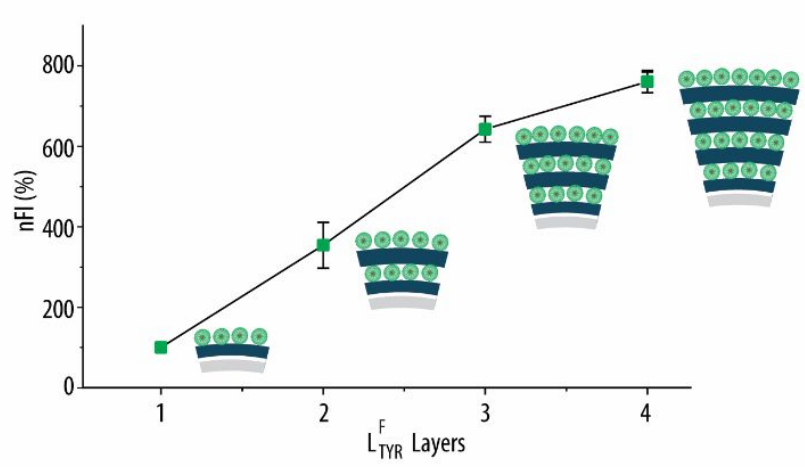

Figure 3. Build-up of tyrosinase (TYR)-loaded liposomes ( $\left.\mathrm{L}_{\mathrm{TYR}}\right)$ onto poly(D,L-lactic-co-glycolic acid) (PLGA) microspheres. Normalized fluorescence intensity (nFI) readings monitored after the addition of fluorescently labelled $\mathrm{L}_{\mathrm{TYR}}\left(\mathrm{L}^{\mathrm{F}} \mathrm{TYR}\right)$ onto poly(allylamine hydrochloride) (PAH)-coated PLGA microspheres. In between each $\mathrm{L}^{\mathrm{F}}{ }_{\mathrm{TYR}}$ deposition step, a PAH separation layer is required. The results have been normalized to the first $\mathrm{L}^{\mathrm{F}}{ }_{\text {TYR }}$ deposition step. 

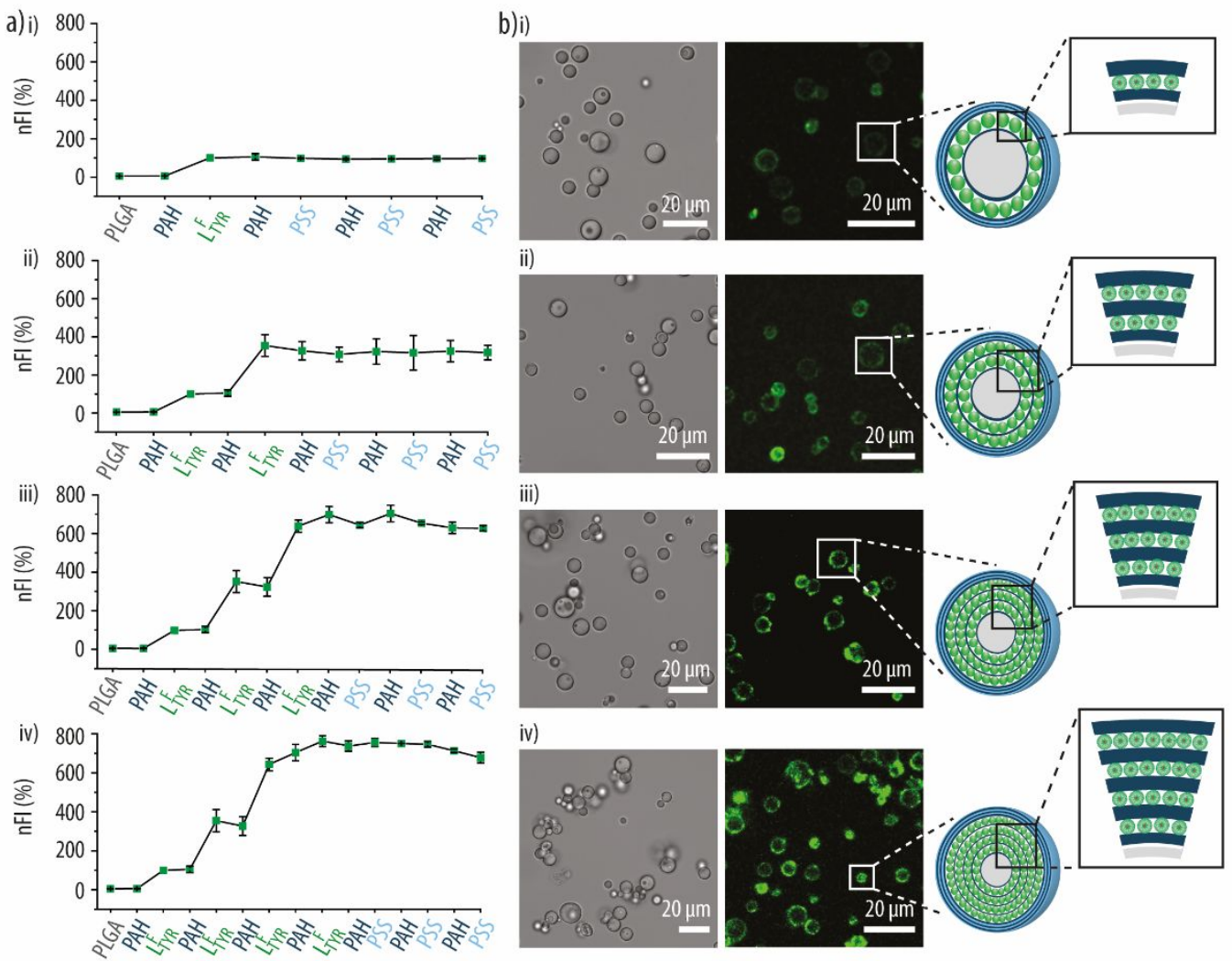

Figure 4. Microreactors characterization. a) Normalized fluorescence intensity (nFI) readings due to the tyrosinase (TYR)-loaded fluorescently labelled liposomes ( $\left.\mathrm{L}^{\mathrm{F}} \mathrm{TYR}\right)$ measured after each deposition step for microreactors containing one (i), two (ii), three (iii) and four (iv) $\mathrm{L}^{\mathrm{F}} \mathrm{TYR}$ deposition steps. The FI has been normalized (nFI) to the FI reading after the first $\mathrm{L}^{\mathrm{F}}{ }_{\text {TYR }}$ deposition step. b) Differential interference contrast (DIC) (left) and fluorescence (right) microscopy images of microreactors containing one (i), two (ii), three (iii) and four (iv) $\mathrm{L}^{\mathrm{F}}$ TYR deposition steps. 

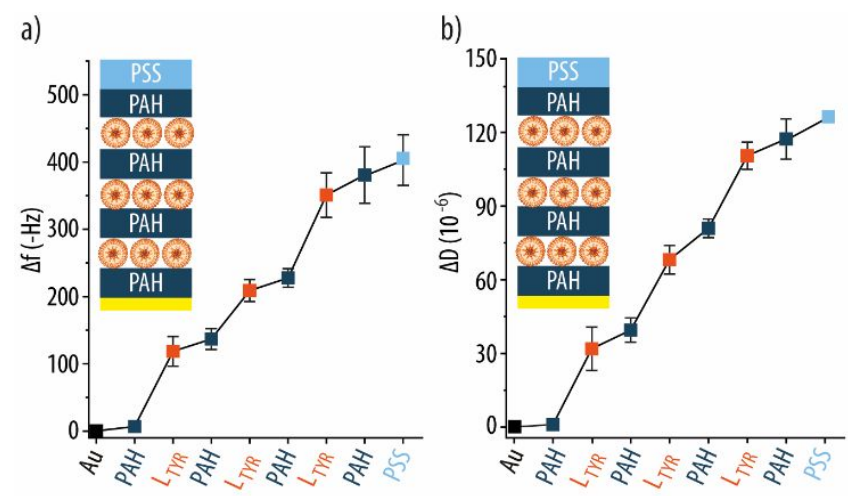

Figure 5. Microreactors characterization by quartz crystal microbalance with dissipation monitoring (QCM-D). Change in frequency $(\Delta \mathrm{f})(\mathrm{a})$ and dissipation $(\Delta \mathrm{D})(\mathrm{b})$ of a QCM-D crystal after each deposition step. 

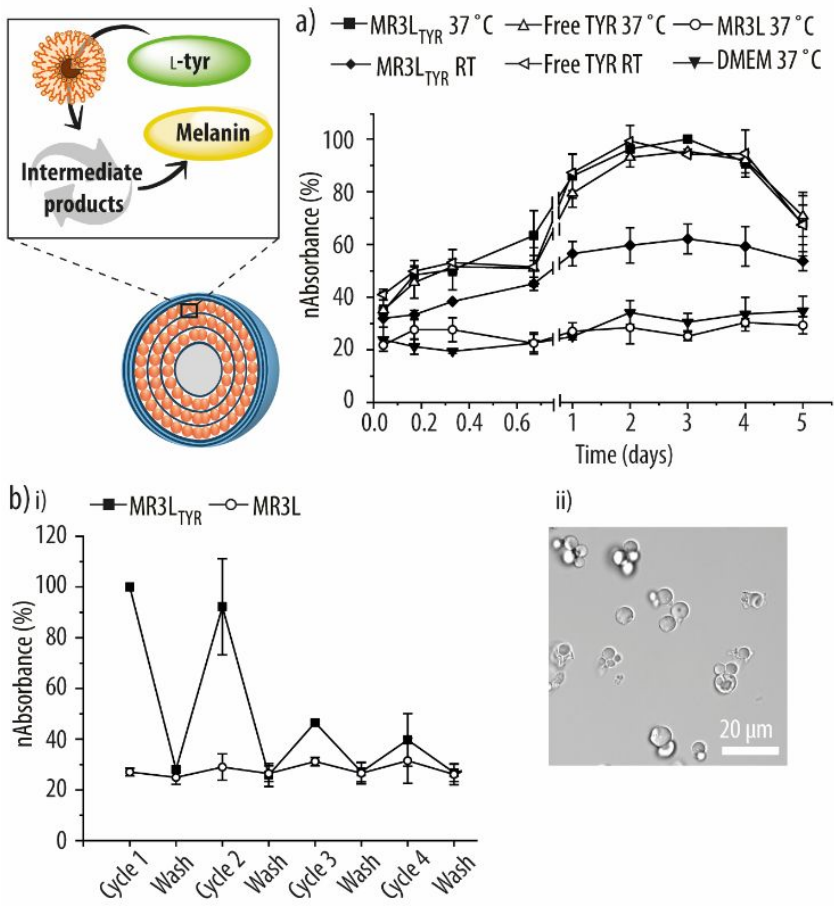

ii)

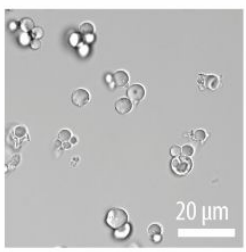

Figure 6. Microreactors functionality. The substrate L-tyrosine (L-tyr) is able to permeate through the polymer shell and the liposomes membrane to interact with the tyrosinase (TYR) enzyme and be converted, by means of several intermediate products, into melanin. a) Enzymatic reaction kinetics of microreactors entrapping three layers of TYR-loaded liposomes $\left(\mathrm{L}_{\mathrm{TYR}}\right)\left(\mathrm{MR} 3 \mathrm{~L}_{\mathrm{TYR}}\right)$ at both $37{ }^{\circ} \mathrm{C}$ and at room temperature (RT), empty microreactors (MR3L) and free TYR incubated in a Dulbecco's Modified Eagle's Medium (DMEM) solution containing L-tyr. A solution of DMEM only is added as a control. The product is measured by monitoring the absorbance of melanin dissolution products at $475 \mathrm{~nm}$. The absorbance readings are normalized to the highest absorbance reading (nAbsorbance). b) i) nAbsorbance readings of the enzymatic reaction of MR3 $\mathrm{L}_{\mathrm{TYR}}$ for four subsequent rounds. As control, MR3L are considered. The absorbance readings have been normalized to the absorbance measurement after the first cycle. ii) Differential interference contrast (DIC) microscopy images of $\mathrm{MR} 3 \mathrm{~L}_{\mathrm{TYR}}$ after the four reaction cycles. 


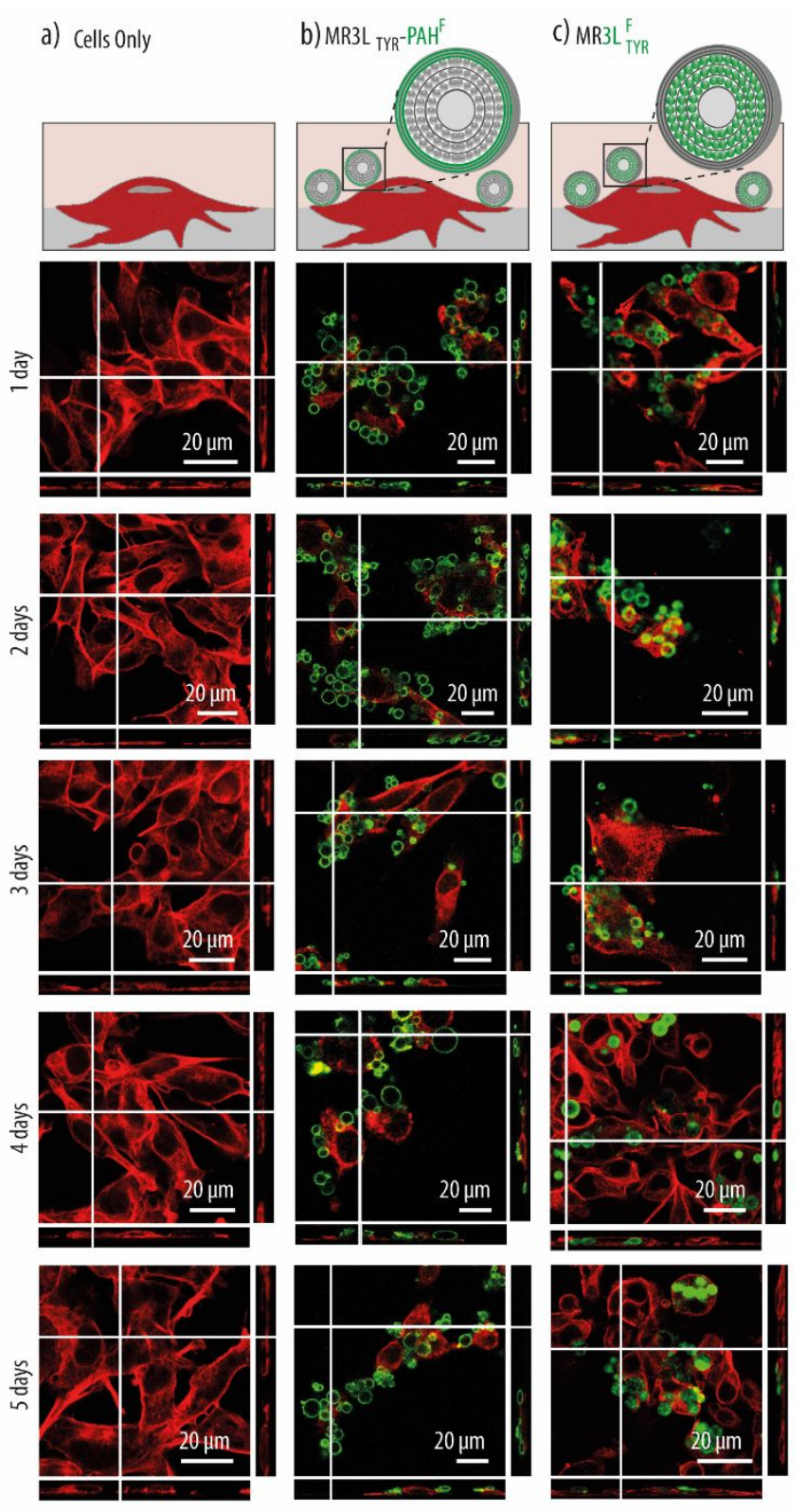

Figure 7. Microreactors integration within melanoma cells. Confocal laser scanning microscopy (CLSM) images of melanoma B16-F10 cells only at different time intervals (a). b) CLSM images of B16-F10 cells co-cultured with microreactors at different time points. The microreactors are encapsulating three layers of tyrosinase (TYR)-loaded liposomes $\left(\mathrm{L}_{\mathrm{TYR}}\right)$ and have been assembled with fluorescently labelled poly(allylamine hydrochloride) $\left(\mathrm{PAH}^{\mathrm{F}}\right)$ to render $\mathrm{MR} 3 \mathrm{~L}_{\mathrm{TYR}} \mathrm{PAH}^{\mathrm{F}}$. c) CLSM images of B16-F10 cells co-cultured with microreactors at different time intervals. The 
microreactors have been assembled employing fluorescently labelled $\mathrm{L}_{\mathrm{TYR}}\left(\mathrm{L}^{\mathrm{F}} \mathrm{TYR}_{\mathrm{R}}\right.$ ) to render MR3 ${ }^{F}{ }_{\text {TYR }}$. Phalloidin-TRITC (red signal) was used to stain the actin filaments of the cells. The green fluorescence signal arises either from $\mathrm{PAH}^{\mathrm{F}}$ or from $\mathrm{L}^{\mathrm{F}}{ }_{\mathrm{TYR}}$. 
a)

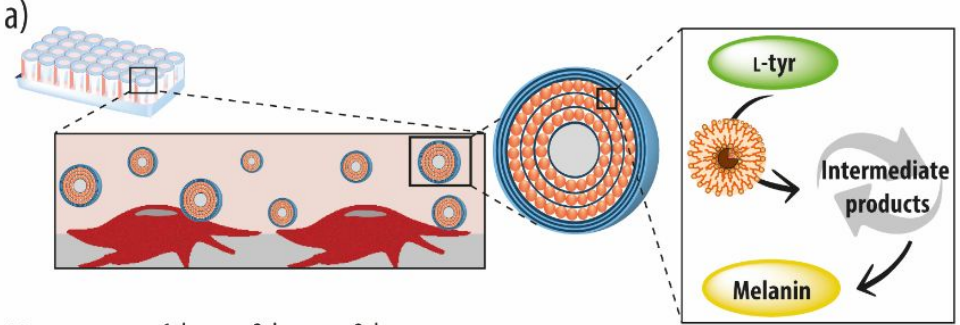

b) $\square 1$ day $\square 2$ days $\square 3$ days

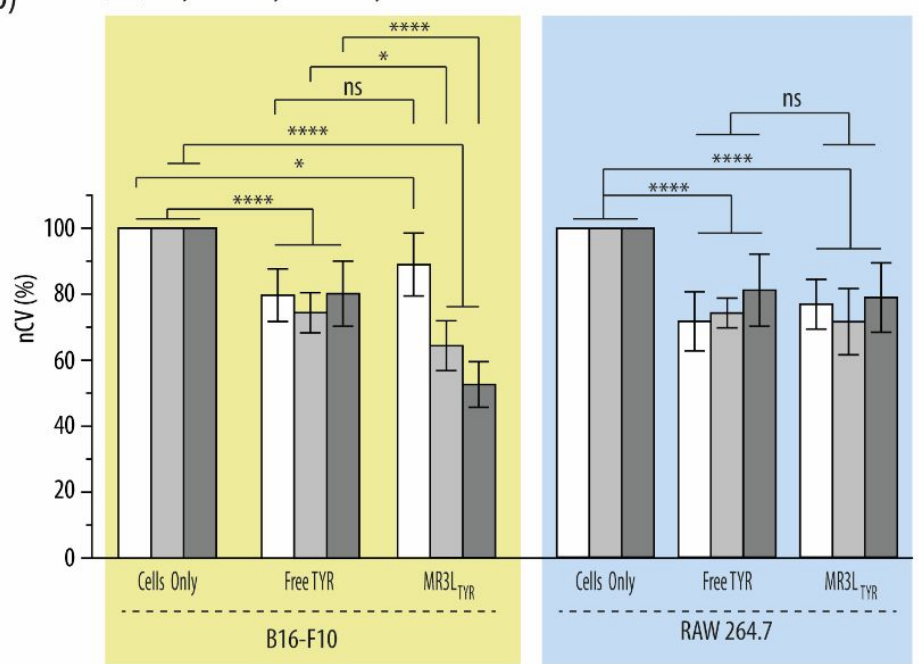

Figure 8. Microreactors activity in vitro. a) In the presence of cells, the substrate L-tyrosine (Ltyr) is able to permeate through the polymer shell and the liposomes membrane to interact with the tyrosinase (TYR) enzyme and be converted, by means of several intermediate products, into melanin. b) Normalized cell viability (nCV) readings of melanoma B16-F10 (left side) and RAW 264.7 (right side) cells exposed to free TYR enzyme and microreactors for different time intervals. The microreactors have been assembled by encapsulating three layers of TYR-loaded liposomes $\left(\mathrm{L}_{\mathrm{TYR}}\right)$ to render MR3 $\mathrm{L}_{\mathrm{TYR}}$. 
a)

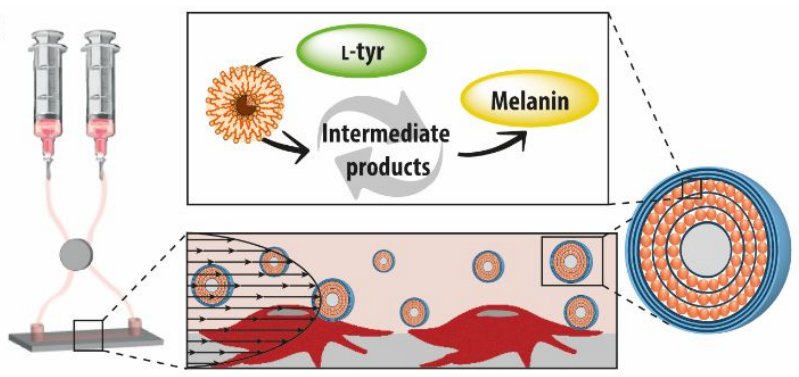

b) $\square$ 1day $\square$ 2days $\square$ 3 days

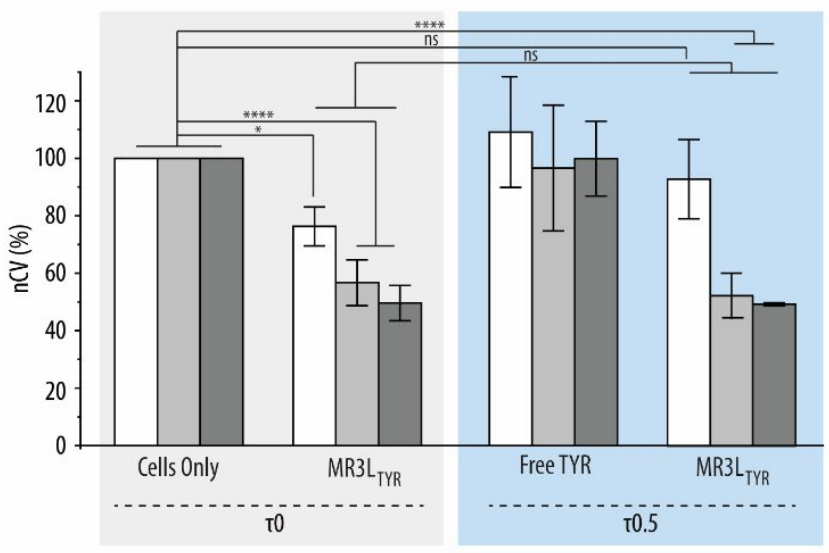

c) $\square$ 1day $\square$ 2days $\square$ 3 days

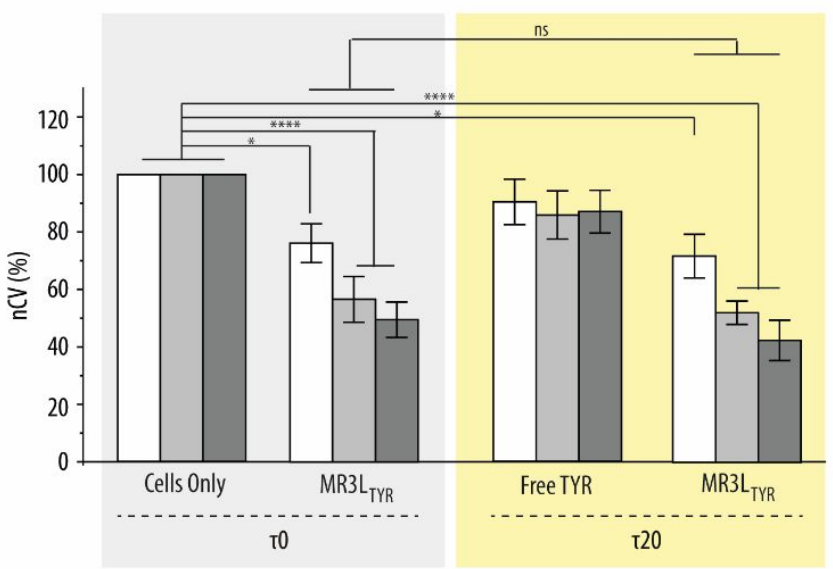

Figure 9. Microreactors activity in a microfluidics set up. a) In the presence of cells and upon applying shear stress, the substrate L-tyrosine (L-tyr) is able to permeate both through the polymer shell and the liposomes membrane to interact with the tyrosinase (TYR) enzyme and be converted, by means of several intermediate products, into melanin. b) Normalized cell viability (nCV) readings of melanoma B16-F10 cells exposed to microreactors in static conditions $(\tau 0)$ and exposed to both free TYR and microreactors at shear stress conditions $\left(\tau=0.5\right.$ dyn $\left.\mathrm{cm}^{-2}, \tau 0.5\right)$ for 
different time intervals. The microreactors are encapsulating three layers of TYR-loaded liposomes $\left(\mathrm{L}_{\mathrm{TYR}}\right)$ to render $\mathrm{MR} 3 \mathrm{~L}_{\mathrm{TYR}}$. c) $\mathrm{nCV}$ readings of melanoma $\mathrm{B} 16-\mathrm{F} 10$ cells exposed to MR3 $\mathrm{L}_{\text {TYR }}$ at $\tau 0$ and to free TYR and MR3 $\mathrm{L}_{\mathrm{TYR}}$ at shear stress conditions $\left(\tau=20\right.$ dyn $\left.\mathrm{cm}^{-2}, \tau 20\right)$ for different time intervals. 


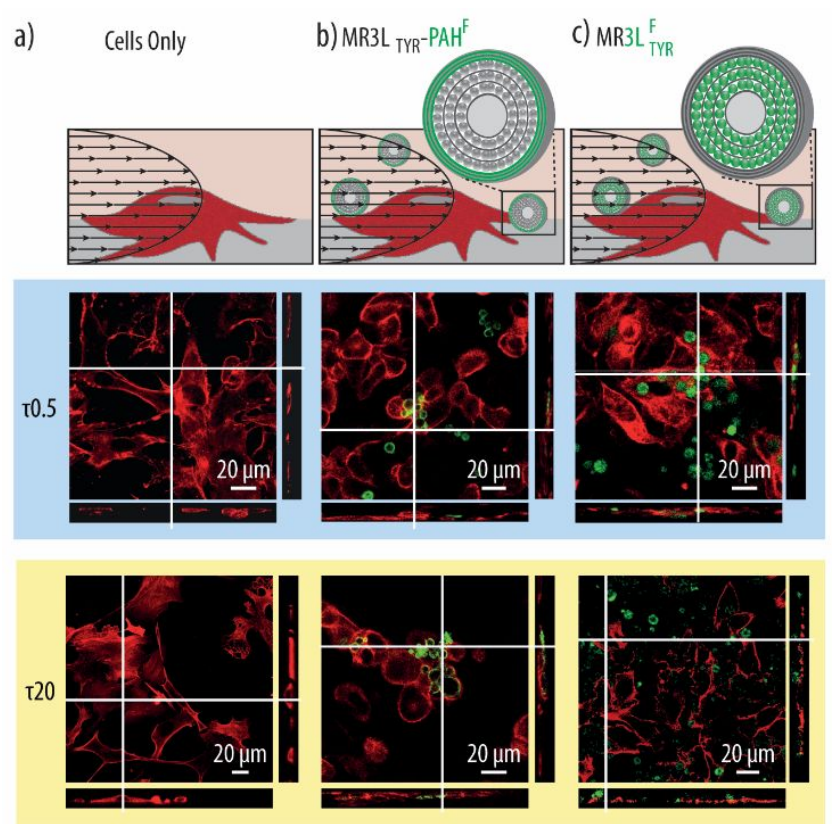

Figure 10. Microreactors integration in a microfluidics set up. Confocal laser scanning microscopy (CLSM) images of melanoma B16-F10 cells only (a) and co-cultured with: b) MR3 $\mathrm{L}_{\text {TYR-PAH }}{ }^{\mathrm{F}}$ microreactors consisting of carriers encapsulating three layers of tyrosinase (TYR)-loaded liposomes $\left(\mathrm{L}_{\mathrm{TYR}}\right)$ and assembled with fluorescently labelled poly(allylamine hydrochloride) $\left(\mathrm{PAH}^{\mathrm{F}}\right)$ or c) MR3 $\mathrm{L}^{\mathrm{F}}{ }_{\text {TYR }}$ microreactors consisting of carriers encapsulating fluorescently labelled $\mathrm{L}_{\mathrm{TYR}}\left(\mathrm{L}^{\mathrm{F}}{ }_{\mathrm{TYR}}\right)$ for different time intervals under the effect of two intra-tumour mimicking shear stresses $\left(\tau=0.5\right.$ dyn $\mathrm{cm}^{-2}(\tau 0.5)$ and $\left.\tau=20 \mathrm{dyn} \mathrm{cm}^{-2}(\tau 20)\right)$. Phalloidin-TRITC (red signal) was used to stain the actin filaments of the cells while the green fluorescence signal results from either fluorescently-labelled $\mathrm{PAH}^{\mathrm{F}}$ or $\mathrm{L}^{\mathrm{F}}{ }_{\mathrm{TYR}}$.

\section{ASSOCIATED CONTENT}

Supporting Information. Mechanism of enzymatic conversion of L-tyrosine into melanin by the enzyme tyrosinase, kinetics of the enzymatic conversion of L-tyrosine into melanin by different amounts of the free tyrosinase enzyme in PBS and in cell media, reaction kinetics of the conversion 
of L-tyrosine into melanin by the enzyme tyrosinase at different temperatures, determination of the encapsulation efficiency of the tyrosinase enzyme within the liposomes, characterization of poly(D,L-lactide-co-glycolide) microspheres, cell viability of empty microreactors at two different microreactors-to-cell ratios (50:1 and 100:1) for B16-F10 melanoma and RAW 264.7 cells, cell viability of B16-F10 melanoma cells exposed to free tyrosinase enzyme in static and shear stress conditions and cell viability of B16-F10 melanoma cells exposed to empty microreactors under shear stress conditions. $\zeta$-potential measurements of the whole assembly.

\section{AUTHOR INFORMATION}

\section{Corresponding Author}

*E-mail: leri@nanotech.dtu.dk

\section{Funding Sources}

This work was supported by the Lundbeck Foundation, Denmark (Grant No. R163-2013-15402).

\section{ACKNOWLEDGMENT}

We gratefully acknowledge Prof. Thomas L. Andresen (DTU Nanotech, Technical University of Denmark) for access to the DLS and CLSM, Prof. Anja Boisen (DTU Nanotech, Technical University of Denmark) for access to the QCM and Prof. Martin Roursgaard (Department of Public Health, Section of Environmental Health, University of Copenhagen) for access to the BD Accuri flow cytometer instrument).

\section{REFERENCES}

(1) Https://Www.Cancer.Net/Cancer-Types/Melanoma/Statistics.

(2) Katsambas, A.; Nicolaidou, E. Cutaneous Malignant Melanoma and Sun Exposure. Recent 
Developments in Epidemiology. Arch. Dermatol. 1996, 132 (4), 444-450.

(3) Https://Www.Cancer.Org/Cancer/Melanoma-Skin-Cancer/about/Key-Statistics.Html.

(4) Azijli, K.; Stelloo, E.; Peters, G. J.; VAN DEN Eertwegh, A. J. M. New Developments in the Treatment of Metastatic Melanoma: Immune Checkpoint Inhibitors and Targeted Therapies. Anticancer Res. 2014, 34 (4), 1493-1505.

(5) Gladfelter, P.; Darwish, N. H. E.; Mousa, S. A. Current Status and Future Direction in the Management of Malignant Melanoma. Melanoma Res. 2017, 27 (5), 403-410.

(6) Letellier, S.; Garnier, J. P.; Spy, J.; Stoitchkov, K.; Le Bricon, T.; Baccard, M.; Revol, M.; Kerneis, Y.; Bousquet, B. Development of Metastases in Malignant Melanoma Is Associated with an Increase in the Plasma L-Dopa/L-Tyrosine Ratio. Melanoma Res. 1999, $9(4), 389-394$.

(7) Elmer, G. W.; Linden, C.; Meadows, G. G. Influence of L-Tyrosine Phenol-Lyase on the Growth and Metabolism of B16 Melanoma. Cancer Treat. Rep. 1979, 63 (6), 1055-1062.

(8) Yu, B.; Chang, T. M. S. Effects of Long-Term Oral Administration of Polymeric Microcapsules Containing Tyrosinase on Maintaining Decreased Systemic Tyrosine Levels in Rats. J. Pharm. Sci. 2004, 93 (4), 831-837.

(9) Fu, Y.; Yu, Z.; Ferrans, V. J.; Meadows, G. G. Tyrosine and Phenylalanine Restriction Induces G0/G1 Cell Cycle Arrest in Murine Melanoma in Vitro and in Vivo. Nutr. Cancer 1997, $29(2), 104-113$.

(10) Pelayo, B. A.; Fu, Y. M.; Meadows, G. G. Decreased Tissue Plasminogen Activator and Increased Plasminogen Activator Inhibitors and Increased Activator Protein-1 and Specific Promoter 1 Are Associated with Inhibition of Invasion in Human A375 Melanoma Deprived of Tyrosine and Phenylalanine. Int. J. Oncol. 2001, 18 (4), 877-883. 
(11) Pelayo, B. A.; Fu, Y. M.; Meadows, G. G. Inhibition of B16BL6 Melanoma Invasion by Tyrosine and Phenylalanine Deprivation Is Associated with Decreased Secretion of Plasminogen Activators and Increased Plasminogen Activator Inhibitors. Clin. Exp. Metastasis 1999, 17 (10), 841-848.

(12) Meadows, G. G.; Pierson, H. F.; Abdallah, R. M.; Desai, P. R. Dietary Influence of Tyrosine and Phenylalanine on the Response of B16 Melanoma to Carbidopa-Levodopa Methyl Ester Chemotherapy. Cancer Res. 1982, 42 (8), 3056-3063.

(13) Lorincz, A. B.; Kuttner, R. E.; Brandt, M. B. Tumor Response to Phenylalanine-TyrosineLimited Diets. J. Am. Diet. Assoc. 1969, 54 (3), 198-205.

(14) D’Mello, S. A. N.; Finlay, G. J.; Baguley, B. C.; Askarian-Amiri, M. E. Signaling Pathways in Melanogenesis. Int. J. Mol. Sci. 2016, 17 (7), 1144-1162.

(15) Rombach, S. M.; Hollak, C. E.; Linthorst, G. E.; Dijkgraaf, M. G. Cost-Effectiveness of Enzyme Replacement Therapy for Fabry Disease. Orphanet J. Rare Dis. 2013, 8 (1), 2938.

(16) Yu, B.; Chang, T. M. S. In Vitro and in Vivo Effects of Polyhaemoglobin-Tyrosinase on Murine B16F10 Melanoma. Melanoma Res. 2004, 14 (3), 197-202.

(17) Yu, B.; Chang, T. M. S. In Vitro and in Vivo Enzyme Studies of PolyhemoglobinTyrosinase. Biotechnol. Bioeng. 2004, 86 (7), 835-841.

(18) Yu, B.; Chang, T. M. S. Effects of Long-Term Oral Administration of Polymeric Microcapsules Containing Tyrosinase on Maintaining Decreased Systemic Tyrosine Levels in Rats. J. Pharm. Sci. 2004, 93 (4), 831-837.

(19) Modery-Pawlowski, C. L.; Tian, L. L.; Pan, V.; Sen Gupta, A. Synthetic Approaches to RBC Mimicry and Oxygen Carrier Systems. Biomacromolecules 2013, 14 (4), 939-948. 
(20) Sen Gupta, A. Bio-Inspired Nanomedicine Strategies for Artificial Blood Components. Wiley Interdiscip. Rev. Nanomed. Nanobiotechnol. 2017, 9 (6), e1464-e1497.

(21) Itel, F.; Schattling, P. S.; Zhang, Y. Enzymes as Key Features in Therapeutic Cell Mimicry. Adv. Drug Delivery Rev. 2017, 118, 94-108.

(22) Godoy-Gallardo, M.; York-Duran, M. J.; Hosta-Rigau, L. Recent Progress in Micro/Nanoreactors toward the Creation of Artificial Organelles. Adv. Healthcare Mater. 2018, 7 (5), 1700917.

(23) York-Duran, M. J.; Godoy-Gallardo, M.; Labay, C.; Urquhart, A. J.; Andresen, T. L.; HostaRigau, L. Recent Advances in Compartmentalized Synthetic Architectures as Drug Carriers, Cell Mimics and Artificial Organelles. Colloids Surf., B 2017, 152, 199-213.

(24) Municoy, S.; Bellino, M. G. A Liposome-Actuated Enzyme System and Its Capability as a Self-Biomineralized Silica Nanoreactor. $R S C A d v$. 2017, 7 (1), 67-70.

(25) Einfalt, T.; Witzigmann, D.; Edlinger, C.; Sieber, S.; Goers, R.; Najer, A.; Spulber, M.; Onaca-Fischer, O.; Huwyler, J.; Palivan, C. G. Biomimetic Artificial Organelles with in Vitro and in Vivo Activity Triggered by Reduction in Microenvironment. Nat. Commun. 2018, $9(1), 1127$.

(26) Garni, M.; Einfalt, T.; Lomora, M.; Car, A.; Meier, W.; Palivan, C. G. Artificial Organelles: Reactions inside Protein-Polymer Supramolecular Assemblies. Chim. Int. J. Chem. 2016, $70(6), 424-427$.

(27) Price, A. D.; Zelikin, A. N.; Wang, Y.; Caruso, F. Triggered Enzymatic Degradation of DNA within Selectively Permeable Polymer Capsule Microreactors. Angew. Chemie - Int. Ed. 2009, 48 (2), 329-332.

(28) Reddy, M. K.; Labhasetwar, V. Nanoparticle-Mediated Delivery of Superoxide Dismutase 
to the Brain: An Effective Strategy to Reduce Ischemia-Reperfusion Injury. FASEB J. 2009, $23(5), 1384-1395$.

(29) Singhal, A.; Morris, V. B.; Labhasetwar, V.; Ghorpade, A. Nanoparticle-Mediated Catalase Delivery Protects Human Neurons from Oxidative Stress. Cell Death Dis. 2013, 4 (11), e903.

(30) Lin, Y. H.; Chen, Y. P.; Liu, T. P.; Chien, F. C.; Chou, C. M.; Chen, C. T.; Mou, C. Y. Approach to Deliver Two Antioxidant Enzymes with Mesoporous Silica Nanoparticles into Cells. ACS Appl. Mater. Interfaces 2016, 8 (28), 17944-17954.

(31) Chang, F.-P.; Hung, Y.; Chang, J.-H.; Lin, C.-H.; Mou, C.-Y. Enzyme Encapsulated Hollow Silica Nanospheres for Intracellular Biocatalysis. ACS Appl. Mater. Interfaces 2014, 6 (9), 6883-6890.

(32) Städler, B.; Chandrawati, R.; Goldie, K.; Caruso, F. Capsosomes: Subcompartmentalizing Polyelectrolyte Capsules Using Liposomes. Langmuir 2009, 25 (12), 6725-6732.

(33) Städler, B.; Chandrawati, R.; Price, A. D.; Chong, S.-F.; Breheney, K.; Postma, A.; Connal, L. A.; Zelikin, A. N.; Caruso, F. A Microreactor with Thousands of Subcompartments: Enzyme-Loaded Liposomes within Polymer Capsules. Angew. Chemie - Int. Ed. 2009, 48 (24), 4359-4362.

(34) Chandrawati, R.; Chong, S.-F.; Zelikin, A. N.; Hosta-Rigau, L.; Städler, B.; Caruso, F. Degradation of Liposomal Subcompartments in PEGylated Capsosomes. Soft Matter 2011, $7(20), 9638$.

(35) Hosta-Rigau, L.; York-Duran, M. J.; Kang, T. S.; Städler, B. Extracellular Microreactor for the Depletion of Phenylalanine Toward Phenylketonuria Treatment. Adv. Funct. Mater. 2015, 25 (25), 3860-3869. 
(36) Godoy-Gallardo, M.; Labay, C.; Trikalitis, V. D.; Kempen, P. J.; Larsen, J. B.; Andresen, T. L.; Hosta-Rigau, L. Multicompartment Artificial Organelles Conducting Enzymatic Cascade Reactions inside Cells. ACS Appl. Mater. Interfaces 2017, 9 (19), 15907-15921.

(37) Hosta-Rigau, L.; Schattling, P.; Teo, B. M.; Lynge, M. E.; Städler, B. Recent Progress of Liposomes in Nanomedicine. J. Mater. Chem. B 2014, 2 (39), 6686-6691.

(38) Qin, G.; Li, Z.; Xia, R.; Li, F.; O’Neill, B. E.; Goodwin, J. T.; Khant, H. A.; Chiu, W.; Li, K. C. Partially Polymerized Liposomes: Stable against Leakage yet Capable of Instantaneous Release for Remote Controlled Drug Delivery. Nanotechnology 2011, 22 (15), 155605 .

(39) Mason, S. D.; Joyce, J. A. Proteolytic Networks in Cancer. Trends Cell Biol. 2011, 21 (4), 228.

(40) Lee, J.; Oh, Y. J.; Lee, S. K.; Lee, K. Y. Facile Control of Porous Structures of Polymer Microspheres Using an Osmotic Agent for Pulmonary Delivery. J. Controlled Release $2010,146(1), 61-67$.

(41) Lee, J.; Oh, Y. J.; Lee, S. K.; Lee, K. Y. Facile Control of Porous Structures of Polymer Microspheres Using an Osmotic Agent for Pulmonary Delivery. J. Controlled Release $2010,146(1), 61-67$.

(42) Sánchez-Ferrer, Á.; Neptuno Rodríguez-López, J.; García-Cánovas, F.; García-Carmona, F. Tyrosinase: A Comprehensive Review of Its Mechanism. Biochim. Biophys. Acta - Protein Struct. Mol. Enzymol. 1995, 1247 (1), 1-11.

(43) Satooka, H.; Cerda, P.; Kim, H.-J.; Wood, W. F.; Kubo, I. Effects of Matsutake Mushroom Scent Compounds on Tyrosinase and Murine B16-F10 Melanoma Cells. Biochem. Biophys. Res. Commun. 2017, 487 (4), 840-846. 
(44) Hu, D.-N. Methodology for Evaluation of Melanin Content and Production of Pigment Cells in Vitro. Photochem. Photobiol. 2008, 84 (3), 645-649.

(45) Godoy-Gallardo, M.; Labay, C.; Jansman, M. M. T.; Ek, P. K.; Hosta-Rigau, L. Intracellular Microreactors as Artificial Organelles to Conduct Multiple Enzymatic Reactions Simultaneously. Adv. Healthcare Mater. 2017, 6 (4), 1601190.

(46) Zhang, Y.; Baekgaard-Laursen, M.; Städler, B. Small Subcompartmentalized Microreactors as Support for Hepatocytes. Adv. Healthcare Mater. 2017, 6 (15), 1601141.

(47) Armada-Moreira, A.; Thingholm, B.; Andreassen, K.; Sebastião, A. M.; Vaz, S. H.; Städler, B. On the Assembly of Microreactors with Parallel Enzymatic Pathways. Adv. Biosyst. 2018, 2 (5), 1700244.

(48) Thingholm, B.; Schattling, P.; Zhang, Y.; Städler, B. Subcompartmentalized Nanoreactors as Artificial Organelle with Intracellular Activity. Small 2016, 12 (13), 1806-1814.

(49) Hosta-Rigau, L.; York-Duran, M. J.; Zhang, Y.; Goldie, K. N.; Städler, B. Confined Multiple Enzymatic (Cascade) Reactions within Poly(Dopamine)-Based Capsosomes. ACS Appl. Mater. Interfaces 2014, 6 (15), 12771-12779.

(50) Zhu, C.; Taipaleenmäki, E. M.; Zhang, Y.; Han, X.; Städler, B. Interaction of Cells with Patterned Reactors. Biomater. Sci. 2018, 6 (4), 793-802.

(51) Donath, E.; Sukhorukov, G. B.; Caruso, F.; Davis, S. A.; Möhwald, H. Novel Hollow Polymer Shells by Colloid-Templated Assembly of Polyelectrolytes. Angew. Chemie Int. Ed. 1998, 37 (16), 2201-2205.

(52) Gittins, D. I.; Caruso, F. Multilayered Polymer Nanocapsules Derived from Gold Nanoparticle Templates. Adv. Mater. 2000, 12 (24), 1947-1949.

(53) Kato, N.; Schuetz, P.; Fery, A.; Caruso, F. Thin Multilayer Films of Weak Polyelectrolytes 
on Colloid Particles. Macromolecules 2002, 35 (26), 9780-9787.

(54) Irigoyen, J.; Moya, S. E.; Iturri, J. J.; Llarena, I.; Azzaroni, O.; Donath, E. Specific לPotential Response of Layer-by-Layer Coated Colloidal Particles Triggered by Polyelectrolyte Ion Interactions. Langmuir 2009, 25 (6), 3374-3380.

(55) Jing, Y.; Trefna, H.; Persson, M.; Kasemo, B.; Svedhem, S. Formation of Supported Lipid Bilayers on Silica: Relation to Lipid Phase Transition Temperature and Liposome Size. Soft Matter 2014, 10 (1), 187-195.

(56) Chandrawati, R.; Hosta-Rigau, L.; Vanderstraaten, D.; Lokuliyana, S. A.; Städler, B.; Albericio, F.; Caruso, F. Engineering Advanced Capsosomes: Maximizing the Number of Subcompartments, Cargo Retention, and Temperature-Triggered Reaction. ACS Nano 2010, 4 (3), 1351-1361.

(57) Hosta-Rigau, L.; Stadler, B.; Yan; Nice, E. C.; Heath, J. K.; Aibericio, F.; Caruso, F. Capsosomes with Multilayered Subcompartments: Assembly and Loading with Hydrophobic Cargo. Adv. Funct. Mater. 2010, 20 (1), 59-66.

(58) Buddingh, B. C.; Van Hest, J. C. M. Artificial Cells: Synthetic Compartments with Lifelike Functionality and Adaptivity. Acc. Chem. Res. 2017, 50 (4), 769-777.

(59) Li, W.; Lee, S.; Ma, M.; Kim, S. M.; Guye, P.; Pancoast, J. R.; Anderson, D. G.; Weiss, R.; Lee, R. T.; Hammond, P. T. Microbead-Based Biomimetic Synthetic Neighbors Enhance Survival and Function of Rat Pancreatic $\beta$-Cells. Sci. Rep. 2013, 3 (1), 2863.

(60) Armada-Moreira, A.; Taipaleenmäki, E.; Baekgaard-Laursen, M.; Schattling, P. S.; Sebastião, A. M.; Vaz, S. H.; Städler, B. Platinum Nanoparticle-Based Microreactors as Support for Neuroblastoma Cells. ACS Appl. Mater. Interfaces 2018, 10 (9), 7581-7592.

(61) Düzgüneş, N.; Faneca, H.; Lima, M. C. Methods to Monitor Liposome Fusion, 
Permeability, and Interaction with Cells. Methods Mol Biol. 2010, 606, 209-232.

(62) Koblinski, J. E.; Ahram, M.; Sloane, B. F. Unraveling the Role of Proteases in Cancer. Clin. Chim. Acta 2000, 291 (2), 113-135.

(63) Zhang, Y.; Schattling, P. S.; Itel, F.; Städler, B. Planar and Cell Aggregate-Like Assemblies Consisting of Microreactors and HepG2 Cells. ACS Omega 2017, 2 (10), 7085-7095.

(64) Itel, F.; Skovhus Thomsen, J.; Städler, B. Matrix Vesicles-Containing Microreactors as Support for Bone-Like Osteoblast Cells to Enhance Biomineralization. ACS Appl. Mater. Interfaces 2018, acsami.8b10886.

(65) Kim, D.; Lin, Y. S.; Haynes, C. L. On-Chip Evaluation of Shear Stress Effect on Cytotoxicity of Mesoporous Silica Nanoparticles. Anal. Chem. 2011, 83, 8377-8382.

(66) Hosta-Rigau, L.; Stadler, B. Shear Stress and Its Effect on the Interaction of Myoblast Cells with Nanosized Drug Delivery Vehicles. Mol Pharm 2013.

(67) Godoy-Gallardo, M.; Ek, P. K.; Jansman, M. M. T.; Wohl, B. M.; Hosta-Rigau, L. Interaction between Drug Delivery Vehicles and Cells under the Effect of Shear Stress. Biomicrofluidics 2015, 9, 1-19.

(68) Michor, F.; Liphardt, J.; Ferrari, M.; Widom, J. What Does Physics Have to Do with Cancer? Nat. Rev. Cancer 2011, 11, 657-670.

(69) Swartz, M. A.; Lund, A. W. Lymphatic and Interstitial Flow in the Tumour Microenvironment: Linking Mechanobiology with Immunity. Nat. Rev. Cancer 2012, 12, $210-219$.

(70) Mitchell, M. J.; King, M. R. Fluid Shear Stress Sensitizes Cancer Cells to ReceptorMediated Apoptosis via Trimeric Death Receptors. New J. Phys. 2013, 15, 015008. 


\section{SYNOPSIS}

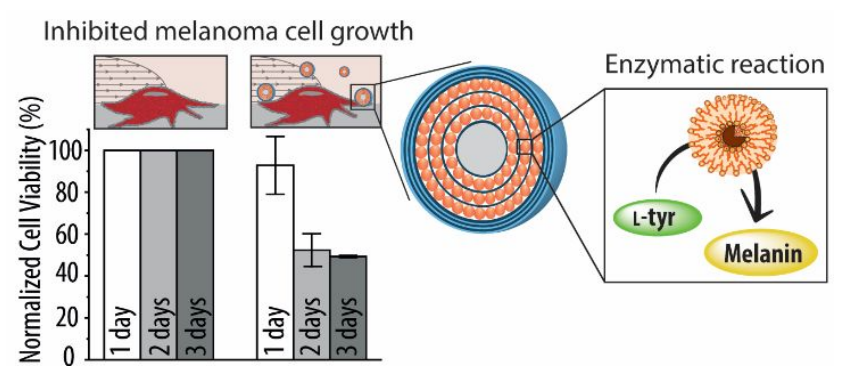

